\title{
The Log-Odd Normal Generalized Family of Distributions with Application
}

\section{MUHAMMAD ZUBAIR ${ }^{1}$, TIBOR K. POGÁNY ${ }^{2}$, GAUSS M. CORDEIRO ${ }^{3}$ and MUHAMMAD H. TAHIR ${ }^{4}$}

\author{
${ }^{1}$ Department of Statistics, Government S.E. College, Bahawalpur, 63100, Pakistan \\ ${ }^{2}$ Faculty of Maritime Studies, University of Rijeka, HR-51000 Rijeka, Croatia \& Applied \\ Mathematics Institute, Óbuda University, H-1034 Budapest, Hungary \\ ${ }^{3}$ Departamento de Estatística, Universidade Federal de Pernambuco, Av. Prof. Moraes Rego, 1235, Cidade Universitária, \\ 50740-540 Recife, PE, Brazil \\ ${ }^{4}$ Department of Statistics, The Islamia University of Bahawalpur, Bahawalpur, 63100, Pakistan
}

Manuscript received on March 20, 2018; accepted for publication on July 17, 2018

\begin{abstract}
How to cite: ZUBAIR M, POGÁNY TK, GAUSS MC AND TAHIR MH. 2019. The Log-Odd Normal Generalized Family of Distributions with Application. An Acad Bras Cienc 91: e20180207. DOI 10.1590/10.1590/0001-3765201920180207.
\end{abstract}

\begin{abstract}
The normal distribution has a central place in distribution theory and statistics. We propose the log-odd normal generalized (LONG) family of distributions based on log-odds and obtain some of its mathematical properties including a useful linear representation for the new family. We investigate, as a special model, the log-odd normal power-Cauchy (LONPC) distribution. Some structural properties of LONPC distribution are obtained including quantile function, ordinary and incomplete moments, generating function and some asymptotics. We estimate the model parameters using the maximum likelihood method. The usefulness of the proposed family is proved empirically by means of a real air pollution data set.
\end{abstract}

Key words: Generalized class, maximum likelihood estimation, normal distribution, power-Cauchy distribution, Shannon entropy.

\section{INTRODUCTION}

The normal distribution plays an important role in statistical theory and real data applications. The probability density function (pdf) and cumulative distribution function (cdf) of the normal random variable (rv) $\mathrm{T}$ with mean $\mu=0$ and standard deviation $\lambda>0$, say $\mathrm{T} \sim \mathrm{N}\left(0, \lambda^{2}\right)$, are given by

$$
r(t)=\frac{1}{\lambda \sqrt{2 \pi}} \exp \left(-\frac{t^{2}}{2 \lambda^{2}}\right)=\frac{1}{\lambda} \varphi\left(\frac{t}{\lambda}\right) 1_{\mathbb{R}}(t)
$$

and

$$
\mathrm{R}(\mathrm{t})=\Phi\left(\frac{\mathrm{t}}{\lambda}\right)
$$

\footnotetext{
Correspondence to: Muhammad Tahir

E-mail:mtahir.stat@gmail.com

ORCid: http://orcid.org/0000-0002-2157-3997
} 
where $\varphi(\cdot)$ and $\Phi(\cdot)$ denote the pdf and cdf (Laplace function) of the standard normal distribution, respectively, and $1_{S}(x)$ stands for the indicator of the event $\mathrm{x} \in \mathrm{S}$.

Some closely related alternatives and generalizations of the normal distribution have been reported in literature. The half-normal $(\mathrm{HN})$ distribution is obtained when the $\mathrm{N}\left(0, \lambda^{2}\right)$ distribution is folded about the origin, and has been used as a model for left-truncated data, which has applications in many fields (Wiper et al. 2008). Leone et al. (1961) proposed the folded-normal (FN) distribution when the measurement system produces only non-negative measurements from a normally distributed process. When the location parameter $\mu=0$, then the FN rv reduces to the HN rv (Gui et al. 2013). The pdf and cdf of the HN distribution with scale parameter $\lambda>0$ are, respectively, given by

$$
f(x ; \lambda)=\frac{\sqrt{2}}{\lambda \sqrt{\pi}} \exp \left(-\frac{x^{2}}{2 \lambda^{2}}\right) 1_{\mathbb{R}_{+}}(x)
$$

and

$$
\mathrm{F}(\mathrm{x} ; \lambda)=\sqrt{\frac{2}{\pi}} \int_{0}^{\frac{\mathrm{x}}{\lambda}} \exp \left(-\frac{\mathrm{t}^{2}}{2}\right) \mathrm{dt}=2 \Phi\left(\frac{\mathrm{x}}{\lambda}\right)-1=\operatorname{erf}\left(\frac{\mathrm{x}}{\lambda \sqrt{2}}\right) 1_{\mathbb{R}_{+}}(\mathrm{x}),
$$

where $\Phi(\mathrm{x})=\frac{1}{2}\left[1+\operatorname{erf}\left(\frac{\mathrm{x}}{\sqrt{2}}\right)\right]$ and $\operatorname{erf}(\mathrm{x})=\frac{2}{\sqrt{\pi}} \int_{0}^{\mathrm{x}} \mathrm{e}^{-\mathrm{t}^{2}} \mathrm{dt}$ is the error function.

Rogers and Tukey (1972) proposed and studied the properties of the slash-normal (SN) family, which has heavier tails than the normal ones, i.e., it has greater kurtosis. The slash distribution is closely related to the normal distribution and is represented as the quotient of a normal rv (numerator) and the power of a uniform rv (denominator), both independent rvs. Hence, we can say that a rv $\mathrm{S}$ has a slash distribution if it can be represented as $S=Z U^{-1 / q}$, where $\mathrm{Z} \sim \mathrm{N}(0,1)$ is independent of $\mathrm{U} \sim \mathrm{U}(0,1)$ and $\mathrm{q}>0$. In particular, if $\mathrm{q} \rightarrow \infty$, then it follows the standard normal distribution and, for $\mathrm{q}=1$, we obtain the canonic (standard) slash density given by

$$
f(x)= \begin{cases}{[\varphi(0)-\varphi(x)] x^{-2}} & x \neq 0 \\ \varphi(0) / 2 & \mathrm{x}=0 .\end{cases}
$$

O'Hagan and Leonard (1976) pioneered the skew-normal (SN) distribution with asymmetry parameter $\lambda$ (see also Azzalini 1985). We write $X \sim \operatorname{SN}(\lambda)$ if the pdf of $X$ is

$$
\mathrm{f}(\mathrm{x} ; \lambda)=2 \varphi(\mathrm{x}) \Phi(\lambda \mathrm{x}), \quad \mathrm{x} \in \mathbb{R} .
$$

Obviously, $\mathrm{SN}(0)$ denotes the standard normal distribution $\mathrm{N}(0,1)$.

Cooray and Ananda (2008) defined the generalized half-normal (GHN) distribution, which has both monotone and non-monotone hazard rate shapes. The pdf and cdf of the GHN distribution with positive scale parameter $\lambda>0$ and shape parameter $\alpha>0$ are given by

$$
f(x ; \lambda, \alpha)=\sqrt{\frac{2}{\pi}}\left(\frac{\alpha}{x}\right)\left(\frac{x}{\lambda}\right)^{\alpha} \exp \left[-\frac{1}{2}\left(\frac{x}{\lambda}\right)^{2 \alpha}\right] 1_{\mathbb{R}_{+}}(x)
$$

and

$$
\mathrm{F}(\mathrm{x} ; \lambda, \alpha)=2 \Phi\left(\frac{\mathrm{x}^{\alpha}}{\lambda^{\alpha}}\right)-1=\operatorname{erf}\left(\frac{\mathrm{x}^{\alpha}}{\sqrt{2} \lambda^{\alpha}}\right) 1_{\mathbb{R}_{+}}(\mathrm{x}),
$$

respectively. Clearly, for $\alpha=1$, the GHN distribution reduces to the HN distribution. 
Any extended normal distribution becomes flexible when shape parameter(s) are added to the normal density through generalized classes reported in literature. Some published generalizations of the normal distributions provide flexible shapes for their densities and hazard rates. Eugene et al. (2002) and Famoye et al. (2004) proposed the beta-G class and studied some properties of the beta-normal (BN) distribution. Correa et al. (2012) introduced the Kumaraswamy-normal (KwN) distribution by using the Kumaraswamy-G class originally proposed by Cordeiro and de-Castro (2011). Alzaatreh et al. (2014a) introduced the gamma-normal (GaN) distribution from the T-X (Gamma-X and Weibull-X) family defined by Alzaatreh et al. (2013). Alzaatreh et al. (2014b) defined and discussed the T-normal family. Lima et al. (2015) studied the GaN model from the gamma-G class reported by Zografos and Balakrishnan (2009). Cordeiro et al. (2012) introduced the McDonald-normal (McN) distribution using the McDonald-G class pioneered by Alexander et al. (2012). Braga et al. (2016) defined the odd log-logistic normal (OLLN) distribution from the odd log-logistic-G (OLL-G) class proposed by Gleaton and Lynch (2006).

The main objectives of the paper are to define a new extended normal class named the log-odd normal generalized (LONG) family and derive a simple general linear representation for obtaining some of its mathematical properties. It is unfolded as follows. In section 'The LONG FAMILY', we define the LONG family and describe its motivation. In section 'LINEAR REPRESENTATION OF LONG FAMILY DENSITY', a linear representation for the family density is obtained, In section 'MATHEMATICAL PROPERTIES OF LONG FAMILY', we perform a modality analysis and obtain some useful properties of the new family such as asymptotics, moments and generating function. In section 'LONG POWER CAUCHY DISTRIBUTION AND ITS PROPERTIES', some structural properties of a special model of the LONG family, namely the log-odd normal power-Cauchy (LONPC) distribution are investigated along with the maximum likelihood method which is used to estimate the parameters of LONPC model. In section 'APPLICATION AS AN ILLUSTRATION OF LONG FAMILY', the usefulness of the LONGPC model is illustrated by means of a real data set on air pollution data, and prove empirically that the LONPC distribution outperforms some well-known lifetime models. The last section offers some concluding remarks.

\section{THE LONG FAMILY}

Studying the beta-generated family, answering in the same time to the question: Can we use other distributions with different supports as the generators to derive different classes of distributions?, Alzaatreh et al. (2013) have proposed the $T-X$ family of distributions.

Let $r(t)$ be the pdf and $R(t)$ be the cdf of a rv $T \in[a, b]$ for $-\infty<a<b<\infty$ and let $W \circ G(x){ }^{1}$ be a function of a baseline cdf $\mathrm{G}(\mathrm{x})$ defined on a standard probability space $(\Omega, \mathscr{F}, \mathrm{P})$ so that $\mathrm{W} \circ \mathrm{G}(\mathrm{x})$ satisfies the following conditions (Alzaatreh et al. 2013):

(i) $\mathrm{W} \circ \mathrm{G}(\mathrm{x}) \in[\mathrm{a}, \mathrm{b}]$;

(ii) $\mathrm{W} \circ \mathrm{G}(\mathrm{x})$ is differentiable and monotonically non-decreasing, and

(iii) $\lim _{\mathrm{x} \rightarrow-\infty} \mathrm{W} \circ \mathrm{G}(\mathrm{x})=\mathrm{a}$ and $\lim _{\mathrm{x} \rightarrow \infty} \mathrm{W} \circ \mathrm{G}(\mathrm{x})=\mathrm{b}$.

The cdf of the $T-X$ family is defined by

$$
F(x)=\int_{a}^{W \circ G(x)} r(t) d t=R \circ W \circ G(x),
$$

\footnotetext{
${ }^{1}$ Here and in what follows, $x \mapsto f_{1} \circ f_{2}(x)=f_{1}\left(f_{2}(x)\right)$ denotes the composite function of $\mathrm{f}_{1}, \mathrm{f}_{2}$, respectively.
} 
where $\mathrm{W} \circ \mathrm{G}(\mathrm{x})$ satisfies the conditions (i)-(iii).

The pdf corresponding to (4) reduces to (Alzaatreh et al. 2013)

$$
f(x)=r \circ W \circ G(x) \frac{d}{d x} W \circ G(x) .
$$

Let $G(x), g(x), \bar{G}(x)=1-G(x)$ and $Q_{G}(p)=G^{-1}(p)$ be the cdf, pdf, survival function ( $\mathrm{sf}$ ) and $q$ f of a baseline continuous rv. Then, the odds $(\mathrm{O}), \log$-odds $(\mathrm{LO})$ and log-odd ratio $(\mathrm{LOR})$ functions are defined by $\mathrm{O}(\mathrm{x})=$ $[\mathrm{G}(\mathrm{x}) / \overline{\mathrm{G}}(\mathrm{x})], \mathrm{LO}(\mathrm{x})=\ln [\mathrm{G}(\mathrm{x}) / \overline{\mathrm{G}}(\mathrm{x})]$ and $\operatorname{LOR}(\mathrm{x})=\mathrm{LO}^{\prime}(\mathrm{x})=\mathrm{g}(\mathrm{x}) /[\mathrm{G}(\mathrm{x}) \overline{\mathrm{G}}(\mathrm{x})]$, respectively. The use of the odd ratio is becoming very popular and has applications in the fields of reliability and survival analysis, large sample theory, discriminant analysis, among others. The LOR is also a useful measure for modeling data that exhibits non-monotone failure rate. The distributions, being non-monotone in terms of failure rate, are monotone in terms of LOR (see Wang et al. 2003).

Some generalized classes have been proposed using the O-function in literature viz. odd log-logistic-G (Gleaton and Lynch 2006), odd gamma-G (Torabi and Montazeri 2012), odd generalized exponential-G (Tahir et al. 2015), odd Burr-G (Alizadeh et al. 2017), generalized odd half-Cauchy-G (Cordeiro et al. 2017), odd Birnbaum-Saunders-G (Ortega et al. 2016) and odd Weibull-G (Bourguignon et al. 2014). Only two generalized classes have been proposed so far from the LO function called the LO-logistic-G (Torabi and Montazeri 2014) and LO-Gumbel-G (Al-Aqtash et al. 2014, 2015) models (when $\mathrm{x} \in \mathbb{R}$ ).

In this paper, we propose and study a new generalized family by considering the LO function, i.e. $\mathrm{W} \circ \mathrm{G}(\mathrm{x})=\ln [\mathrm{G}(\mathrm{x}) / \overline{\mathrm{G}}(\mathrm{x})]$. Henceforth, we write the short-hands $\mathrm{G}(\mathrm{x}):=\mathrm{G}(\mathrm{x} ; \xi)$ and $\mathrm{F}(\mathrm{x}):=\mathrm{F}(\mathrm{x} ; \lambda, \xi)$ omitting by convention the parameters $\lambda, \xi$ throughout. Then, we define the cdf of the LONG family by

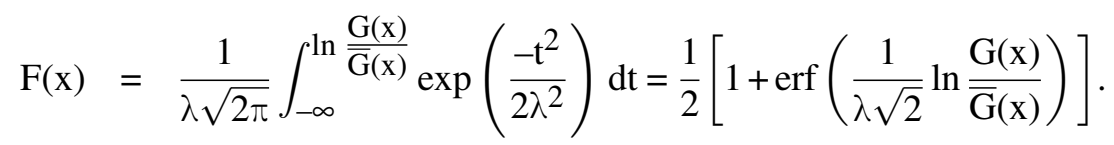

Two interpretations of this family can be given as follow. For the first interpretation, let $\mathrm{T}$ be a rv defined on a standard probability space $(\Omega, \mathscr{F}, \mathrm{P})$ describing a stochastic system by the cdf $\mathrm{G}(\mathrm{x})$. If the rv $\mathrm{X}$ represents the odds, the risk that the system following the lifetime $T$ will be not working at time $\mathrm{x}$ is given by $\mathrm{G}(\mathrm{x}) / \overline{\mathrm{G}}(\mathrm{x})$. If we are interested in modeling the randomness of the $L O$ by the $\operatorname{cdf} \Pi(x)=\Phi\left(\lambda^{-1} \ln x\right) 1_{\mathbb{R}_{+}}(x)$, the cdf of $\mathrm{X}$ is given by

$$
\mathrm{P}(\mathrm{X} \leq \mathrm{x})=\Pi\left(\frac{\mathrm{G}(\mathrm{x})}{\overline{\mathrm{G}}(\mathrm{x})}\right)=\Phi\left(\frac{1}{\lambda} \ln \frac{\mathrm{G}(\mathrm{x})}{\overline{\mathrm{G}}(\mathrm{x})}\right) .
$$

For the second interpretation of (6), we take a LONG rv $X$ and a rv T with $\operatorname{cdf} \Phi\left(\lambda^{-1} \ln \mathrm{t}\right)$, for $\mathrm{t}>0$. Then, $\mathrm{P}(\mathrm{X} \leq \mathrm{x})=\mathrm{F}(\mathrm{x})=\Phi\left(\frac{1}{\lambda} \ln \frac{\mathrm{G}(\mathrm{x})}{\overline{\mathrm{G}}(\mathrm{x})}\right)=\mathrm{P}\left(\mathrm{T} \leq \frac{\mathrm{G}(\mathrm{x})}{\overline{\mathrm{G}}(\mathrm{x})}\right)$. Since the function $\rho(\mathrm{x})=\mathrm{G}(\mathrm{x}) / \overline{\mathrm{G}}(\mathrm{x})$ is always monotonic and non-decreasing, this implies that $\mathrm{T} \stackrel{\mathscr{D}}{=} \rho(\mathrm{X}){ }^{2}$ So, if $\mathrm{X}$ has the LONG distribution, then $\mathrm{T}=\rho(\mathrm{X})$ has cdf given by $\Phi\left(\lambda^{-1} \ln t\right) 1_{\mathbb{R}_{+}}(t)$, holding for every continuous cdf $G(x)$.

Note that the SN distribution is just a special case of the LONG family. In fact, we can obtain Azzalini's model (Azzalini 1985) by taking the Burr type II as baseline G in our LONG cdf (6).

The pdf corresponding to (6) is given by

$$
f(x)=\frac{g(x)}{\lambda \sqrt{2 \pi} G(x) \bar{G}(x)} \exp \left[-\frac{1}{2 \lambda^{2}} \ln ^{2} \frac{G(x)}{\bar{G}(x)}\right],
$$

\footnotetext{
${ }^{2}$ Here, as usual we write $\stackrel{\mathscr{D}}{=}$ for equality of random variables in distribution.
} 
whereas the associated hazard rate function (hrf) becomes

$$
h(x)=\frac{2 g(x)}{\lambda \sqrt{2 \pi} G(x) \bar{G}(x)} \frac{\exp \left[-\frac{1}{2 \lambda^{2}} \ln ^{2} \frac{G(x)}{\bar{G}(x)}\right]}{\left\{1-\operatorname{erf}\left[\frac{1}{\lambda \sqrt{2}} \ln \frac{G(x)}{\bar{G}(x)}\right]\right\}} .
$$

Henceforth, we denote by $\mathrm{X}$ a rv having pdf (7) with parameters $\lambda$ and $\xi$.

We emphasize that hundreds extended distributions have been developed by introducing two or more parameters to a baseline distribution in the last two decades for modeling data in several applied areas such as biology, oncology, environmental and medical sciences, engineering and economics. However, there is a clear need for further simple extended families in these areas, that is, new very flexible models to fit real data that present large intervals for skewness and kurtosis and heavy-tailed shapes. The LONG family aims to fill part of this gap by constructing new flexible distributions with just one additional parameter, while some other known families such as beta and Kumaraswamy have two extra parameters.

Furthermore, the basic motivation for considering the LONG family in practice are the following desired tasks:

(i) have one extra parameter, whereas some known generators such as beta and Kumaraswamy have two;

(ii) make the kurtosis more flexible compared to the baseline model;

(iii) produce a skewness for symmetrical distributions;

(iv) construct heavy-tailed distributions that are not longer-tailed for modeling real data;

(v) generate distributions with symmetric, left-skewed, right-skewed and reversed J-shaped;

(vi) define special models with all types of the hrf;

(vii) provide consistently better fits than other generated models under the same baseline distribution.

Lemma 1. The qf of $\mathrm{X}$ can be obtained by inverting (6) as

$$
\mathrm{Q}(\mathrm{p})=\mathrm{F}^{-1}(\mathrm{p})=\mathrm{Q}_{\mathrm{G}}\left(\frac{\exp \left[\lambda \sqrt{2} \operatorname{erf}^{-1}(2 \mathrm{p}-1)\right]}{1+\exp \left[\lambda \sqrt{2} \operatorname{erf}^{-1}(2 \mathrm{p}-1)\right]}\right) 1_{(0,1)}(\mathrm{p}) .
$$

If $\mathrm{U} \sim \mathrm{U}(0,1)$, the solution of the nonlinear equation $\mathrm{X}=\mathrm{Q}(\mathrm{U})$ possesses $\mathrm{pdf}(7)$.

The next lemma connects the normal distribution and the LONG family.

Lemma 2. If $\mathrm{T} \sim \mathrm{N}\left(0, \lambda^{2}\right)$, then $\mathrm{X}=\mathrm{G}^{-1}\left(\frac{\mathrm{e}^{\mathrm{T}}}{1+\mathrm{e}^{\mathrm{T}}}\right)$ follows the LONG family.

Further, the following two lemmata provide the rth ordinary moment and Shannon entropy of $\mathrm{X}$.

Lemma 3. The rth ordinary moment of $\mathrm{X}$ is given by

$$
\mathbb{E}\left(\mathrm{X}^{\mathrm{r}}\right)=\frac{1}{\lambda \sqrt{2 \pi}} \int_{\mathbb{R}}\left[\mathrm{G}^{-1}\left(\frac{\mathrm{e}^{\mathrm{t}}}{1+\mathrm{e}^{\mathrm{t}}}\right)\right]^{\mathrm{r}} \exp \left(-\frac{\mathrm{t}^{2}}{2 \lambda^{2}}\right) \mathrm{dt} .
$$

The assertion follows from Lemma 2. Moreover, due to non-closed form of the integral in (10) numerical integration can be used to obtain the rth moment of the LONG family and its special models. 
Lemma 4. The Shannon entropy of $X$, when $T \sim N\left(0, \lambda^{2}\right)$, equals to

$$
\eta_{\mathrm{X}}=\ln (\lambda \sqrt{2 \pi \mathrm{e}})-\mathbb{E}\left[\ln \mathrm{g} \circ \mathrm{G}^{-1}\left(\frac{\mathrm{e}^{\mathrm{T}}}{1+\mathrm{e}^{\mathrm{T}}}\right)\right] .
$$

Here, $\mathrm{G}^{-1}(\cdot)$ and $\mathrm{g}(\cdot)$ are the qf and pdf of the parent $\mathrm{G}$ model, respectively.

We omit the proof since it follows by applying the result in Alzaatreh et al. (2013).

\section{LINEAR REPRESENTATION OF LONG FAMILY DENSITY}

Our next task is to establish a power series representation for the $\operatorname{cdf} F(x)$ given by (6) in powers of $H(x)=$ $1-2 G(x)$, where $G(x)$ is the baseline cdf. We take relations from Equations (39) and (40) (consult also Appendix A for notation) by which the algebraic developments are based on well-known hypergeometric functions

$$
\mathrm{F}(\mathrm{x})=\frac{1}{2}\left[1+\frac{\mathrm{w}}{\sqrt{\pi}}{ }_{1} \mathrm{~F}_{1}\left(\frac{1}{2} ; \frac{3}{2} ;-\mathrm{w}^{2}\right)\right],
$$

where

$$
\mathrm{w}=-\frac{\sqrt{2} \mathrm{H}(\mathrm{x})}{\lambda}{ }_{2} \mathrm{~F}_{1}\left(\frac{1}{2}, 1 ; \frac{3}{2} ; \mathrm{H}^{2}(\mathrm{x})\right) .
$$

The inferred form of the cdf given in (12) includes the determination of positive even integer powers of $\mathrm{w}$ (see (39)) which one reduces to the calculation of the coefficients of power series raised to positive integer powers being the zeroth order coefficient equal to unity (consult Appendix B), that is

$$
w^{2 n}=\frac{2^{n} H^{2 n}(x)}{\lambda^{2 n}}\left[1+\sum_{m \geq 1} b_{m} H^{2 m}(x)\right] .
$$

Here, by virtue of (42), we clearly conclude

$$
\mathrm{b}_{0}=1, \quad \mathrm{~b}_{\mathrm{m}}=\sum_{\mathrm{k}=1}^{\mathrm{m}}\left[(\mathrm{n}+1) \frac{\mathrm{k}}{\mathrm{m}}-1\right] \frac{\left(\frac{1}{2}\right)_{\mathrm{k}}(1)_{\mathrm{k}}}{\left(\frac{3}{2}\right)_{\mathrm{k}} \mathrm{k} !} \mathrm{b}_{\mathrm{m}-\mathrm{k}}, \quad \mathrm{m} \in \mathbb{N},
$$

where $(a)_{i}=\Gamma(a+i) / \Gamma(a)=a(a+1) \ldots(a+i-1)$ for $i \geq 0$ is the Pochhammer symbol (or raising factorial). Now, the collected relations (6) and (12)-(14) imply

$$
\mathrm{F}(\mathrm{x})=\frac{1}{2}\left[1-\frac{\sqrt{2} \mathrm{H}(\mathrm{x})}{\lambda \sqrt{\pi}} \sum_{\mathrm{n}, \mathrm{m} \geq 0} \frac{(-1)^{\mathrm{n}}\left(\frac{1}{2}\right)_{\mathrm{n}}}{\left(\frac{3}{2}\right)_{\mathrm{n}} \mathrm{n} !}\left(\frac{\sqrt{2}}{\lambda^{2}}\right)^{\mathrm{n}} \mathrm{b}_{\mathrm{m}} \mathrm{H}^{2(\mathrm{n}+\mathrm{m})+1}(\mathrm{x})\right] .
$$

The multiplication of power series gives

$$
\mathrm{F}(\mathrm{x})=\frac{1}{2}\left(1-\frac{\sqrt{2}}{\lambda \sqrt{\pi}} \sum_{\mathrm{k} \geq 0} \mathrm{c}_{\mathrm{k}}[1-2 \mathrm{G}(\mathrm{x})]^{2 \mathrm{k}+1}\right)
$$

and then

$$
\mathrm{F}(\mathrm{x})=\frac{1}{2}\left[1-\frac{\sqrt{2}}{\lambda \sqrt{\pi}} \sum_{\mathrm{k} \geq 0} \mathrm{c}_{\mathrm{k}} \sum_{\ell=0}^{2 \mathrm{k}+1}(-2)^{\ell}\left(\begin{array}{c}
2 \mathrm{k}+1 \\
\ell
\end{array}\right) \mathrm{G}^{\ell}(\mathrm{x})\right],
$$


where

$$
c_{k}=\sum_{j=0}^{k} \frac{(-1)^{j}\left(\frac{1}{2}\right)_{j}}{\left(\frac{3}{2}\right)_{j} j !}\left(\frac{\sqrt{2}}{\lambda^{2}}\right)^{j} b_{k-j}, \quad k \in \mathbb{N}_{0} .
$$

Next, since $G^{\prime}(x)=g(x)$, the termwise differentiation of (16) gives the pdf of $X$ as

$$
f(x)=\frac{g(x)}{\sqrt{2} \lambda \sqrt{\pi}} \sum_{k \geq 0} c_{k} \sum_{\ell=0}^{2 k}(-1)^{\ell}(\ell+1) 2^{\ell}\left(\begin{array}{c}
2 k+1 \\
\ell+1
\end{array}\right) G^{\ell}(x) .
$$

By using Bailey's transformation (Slater 1996;p.58) in (18) to interchange $\sum_{\mathrm{k} \geq 0} \sum_{\ell=0}^{2 \mathrm{k}}$ with the equivalent summation $\sum_{\ell \geq 0} \sum_{\mathrm{k}}: 2 \mathrm{k} \geq \ell$ (see Srivastava and Manocha 1984;p.100, Lemma 2), we obtain

$$
f(x)=\frac{g(x)}{\sqrt{2} \lambda \sqrt{\pi}} \sum_{\ell \geq 0}(-1)^{\ell}(\ell+1) 2^{\ell}\left\{\sum_{k: 2 k \geq \ell} c_{k}\left(\begin{array}{c}
2 k+1 \\
\ell+1
\end{array}\right)\right\} G^{\ell}(x) .
$$

The LONG family pdf follows from the last equation as

$$
f(x)=\frac{g(x)}{\sqrt{2} \lambda \sqrt{\pi}} \sum_{\ell \geq 0} c_{k} \sum_{k \geq\left\lfloor\frac{\ell}{2}\right\rfloor}(-1)^{\ell}(\ell+1) 2^{\ell}\left(\begin{array}{c}
2 k+1 \\
\ell+1
\end{array}\right) G^{\ell}(x),
$$

where $\lfloor z\rfloor$ is the greatest integer less than or equal to $z$.

The exponentiated-G family with power parameter $\alpha>0$, say exp-G( $\alpha)$, has pdf given by $h_{\alpha}(x)=$ $\alpha \mathrm{g}(\mathrm{x}) \mathrm{G}^{\alpha-1}(\mathrm{x})$. The corresponding cdf turns out to be $\mathrm{H}_{\alpha}(\mathrm{x})=\mathrm{G}^{\alpha}(\mathrm{x})$. Clearly, $\mathrm{h}_{1}(\mathrm{x})$ is the baseline pdf $\mathrm{g}(\mathrm{x})$. For an associated rv $\mathrm{Y}$ this correspondence is denoted by $\mathrm{Y} \sim \exp -\mathrm{G}(\alpha)$. Several properties of exp-G distributions have been studied by many authors in recent years.

Equation (19) can be reduced to

$$
\mathrm{f}(\mathrm{x})=\sum_{\ell \geq 0} \omega_{\ell} \mathrm{h}_{\ell+1}(\mathrm{x})
$$

where

$$
\omega_{\ell}=\frac{(-1)^{\ell} 2^{\ell}}{\sqrt{2} \lambda \sqrt{\pi}} \sum_{\mathrm{k} \geq\left\lfloor\frac{\ell}{2}\right\rfloor} c_{\mathrm{k}}\left(\begin{array}{c}
2 \mathrm{k}+1 \\
\ell+1
\end{array}\right), \quad \ell \in \mathbb{N}_{0},
$$

and $h_{\ell+1}(x)=(\ell+1) g(x) G^{\ell}(x)$ is the exp-G density with power parameter $\ell+1$ (for $\ell \geq 0$ ).

Equation (20) reveals that the LONG family density can be represented by an infinite linear combination of exp-G densities. However, this mutually means that the pdf/cdf of the LONG family possesses a linear representation in terms of the pdf/cdf of the associated exp-G random variable. Thus, some mathematical properties of the proposed family can be derived from those properties of the exp-G class. We emphasize that more than thirty five exp-G distributions have been published so far. All these distributions can be used to generate new special models of the LONG family. Clearly, we can obtain directly from the linear representation some of their structural properties from those exp-G properties.

\section{MATHEMATICAL PROPERTIES OF LONG FAMILY}

The formulae derived throughout the paper can be easily handled in most symbolic computation software platforms such as Maple, Mathematica and Matlab. These platforms have currently the ability to deal 
with analytic expressions of formidable size and complexity. Established explicit expressions to calculate statistical measures can be more efficient than computing them directly by numerical integration.

MODALITY ANALYSIS OF LONG FAMILY. The modality analysis of a continuous distribution includes as starting point the number and magnitudes of the related pdf's peaks. The rv X belonging to the LONG family is determined by the $\operatorname{pdf} \mathrm{f}(\mathrm{x})$ given in (7), and then the stationary points set associated with the maxima consists from the values for which $[\ln f(x)]^{\prime}=0$. Assuming that the baseline cdf $y=G(x)$ is twice differentiable, the results are the roots of the second-order nonlinear ordinary differential equation (ODE)

$$
y(1-y) y^{\prime \prime}=y^{\prime 2}\left(1-2 y+\frac{1}{\lambda^{2}} \ln \frac{y}{1-y}\right) .
$$

Obviously, we consider this equation inside the set $\operatorname{supp}(\mathrm{f})=\{\mathrm{x}: \mathrm{f}(\mathrm{x})>0\}$. For the solution by setting $\mathrm{u}=$ $\mathrm{u}(\mathrm{y})=\mathrm{y}^{\prime}$ and reducing $(21)$, we obtain

$$
\mathrm{u}^{\prime}=\frac{1-2 \mathrm{y}+\frac{1}{\lambda^{2}} \ln \frac{\mathrm{y}}{1-\mathrm{y}}}{\mathrm{y}(1-\mathrm{y})} .
$$

Integrating twice, first with respect to $\mathrm{y}$, and then with respect to $\mathrm{x}$, we have

$$
y(x)=\frac{\exp \left\{\lambda \sqrt{2} \operatorname{erf}^{-1}\left(\frac{\sqrt{2} c_{1}}{\lambda \sqrt{\pi}}\left(x+c_{2}\right)\right)\right\}}{1+\exp \left\{\lambda \sqrt{2} \operatorname{erf}^{-1}\left(\frac{\sqrt{2} c_{1}}{\lambda \sqrt{\pi}}\left(x+c_{2}\right)\right)\right\}},
$$

where $\operatorname{erf}^{-1}(\cdot)$ stands for the inverse error function ${ }^{3}$ (the related Mathematica code is InverseErf[x]) and the integration constants $c_{1}, c_{2}$ depend on the form of $G(x)$. For the sake of simplicity, we consider only the case $c_{2}=0$, and then

$$
y(x)=\frac{1}{1+\exp \left\{-\lambda \sqrt{2} \operatorname{erf}^{-1}(\mathrm{cx})\right\}},
$$

where $\mathrm{c}=\mathrm{c}_{\mathrm{G}}(\lambda)=\frac{\sqrt{2} \mathrm{c}_{1}}{\lambda \sqrt{\pi}}>0, \mathrm{y}(\mathrm{x})$ being necessarily normalized.

Next, the saddle point of $y(x)$ is determined from

$$
\begin{aligned}
y^{\prime \prime}(x)= & \frac{\lambda^{2} \pi c^{2} \exp \left\{-\lambda \sqrt{2} \operatorname{erf}^{-1}(\mathrm{cx})+2 \operatorname{erf}^{-1}(\mathrm{cx})^{2}\right\}}{\left(1+\exp \left\{-\lambda \sqrt{2} \operatorname{erf}^{-1}(\mathrm{cx})\right\}\right)^{3}} \\
& \times\left[\left(1+\frac{\lambda}{\sqrt{2}}\right) \operatorname{erf}^{-1}(\mathrm{cx})+\operatorname{erf}^{-1}(\mathrm{cx}) \exp \left\{-\lambda \sqrt{2} \operatorname{erf}^{-1}(\mathrm{cx})\right\}-\frac{\lambda}{\sqrt{2}}\right]=0 .
\end{aligned}
$$

Accordingly, setting $\operatorname{erf}^{-1}(\mathrm{cx})=\mathrm{z}$, the previous equation reduces to

$$
\mathrm{L}(\mathrm{z})=1+\frac{\lambda}{\sqrt{2}}+\mathrm{e}^{-\lambda \sqrt{2} \mathrm{z}}=\frac{\lambda}{\sqrt{2} \mathrm{z}}=\mathrm{R}(\mathrm{z}) .
$$

There is a unique solution $z_{0}=z_{0}(\lambda) \in(0,1)$, say, of the previous equation (22). Indeed, if $\lambda>0$, the left-hand-side expression $\mathrm{L}(\mathrm{z}) \searrow 1+\frac{\lambda}{\sqrt{2}}$ in $\mathrm{z} \rightarrow \infty$ is greater then $\mathrm{R}(1)$. Consequently, the hyperbola $\mathrm{R}(\mathrm{z})$ and

\footnotetext{
${ }^{3}$ The inverse error function $\mathrm{y}=\operatorname{erf}^{-1}(\mathrm{x})$ can be defined as a function which satisfies $\operatorname{erf}^{-1} \circ \operatorname{erf}(\mathrm{x})=\mathrm{x}, \mathrm{x} \in \mathbb{R}$; also it is a particular solution of the nonlinear ODE $\mathrm{y}^{\prime \prime}-\mathrm{yy}^{\prime 2}=0$.
} 
the exponential function $L(z)$ have an unique intersection inside the vertical half-strip $\{z+i \eta: z \in(0,1), \eta \in$ $\left.\mathbb{R}_{+}\right\}$. So, the abscissa of the pdf's peak becomes $x_{0}=\operatorname{erf}\left(z_{0}\right) / c_{G}(\lambda)$. Obviously, the left $z-$ half-plane does not contain any real solution of (22). So, since the stationary point of the $\operatorname{pdf}(7)$ is inside supp(f), the second order non-linear ODE (21) characterizes the peak which describes the mode of the rv X. The rest is obvious.

We can note that (22) should be treated by some of numerical solving methods and it has to be mentioned that the case $c_{2} \neq 0$ cannot harm the previous conclusion.

By these we have proved the following result.

Theorem 5. Let $\mathrm{X}$ be a rv coming form the LONG distribution family having twice continuously differentiable input baseline cdf $\mathrm{G}(\mathrm{x})$. Then, for all $\lambda>0$, the $\mathrm{rv} \mathrm{X}$ is unimodal with the mode

$$
\mathrm{x}_{0}=\frac{\operatorname{erf}\left(\mathrm{z}_{0}\right)}{\mathrm{c}_{\mathrm{G}}(\lambda)}, \quad \mathrm{z}_{0} \in(0,1),
$$

where $\mathrm{z}_{0}=\mathrm{z}_{0}(\lambda)$ is the solution of the auxiliary equation (22).

The shape of the $\operatorname{hrf}(8)$ of $X$ can be described by $f^{\prime}(x)=-f(x) h(x)$, which readily follows from the familiar formula $\mathrm{f}(\mathrm{x})=\mathrm{h}(\mathrm{x}) \exp \left\{-\int_{0}^{\mathrm{x}} \mathrm{h}(\mathrm{t}) \mathrm{dt}\right\}$.

ASYMPTOTICS OF THE CDF AND PDF OF LONG FAMILY. Let us consider the asymptotics of the cdf and pdf of the LONG family near to the infimum of the support interval for the baseline cdf $\mathrm{G}(\mathrm{x})$, and also when the argument is growing to the supremum of the support set.

Proposition 6. Let $\mathrm{c}=\inf _{\mathrm{x}} \operatorname{supp}(\mathrm{G})$. Then, the asymptotics for the $c d f$ and $p d f$ of the LONG family, presented in Equations (6) and (7), respectively, turn out to be

$$
\mathrm{F}(\mathrm{x}) \sim \Phi\left(\lambda^{-1} \ln \mathrm{G}(\mathrm{x})\right), \quad \mathrm{f}(\mathrm{x}) \sim \frac{\mathrm{g}(\mathrm{x})}{\lambda \mathrm{G}(\mathrm{x})} \varphi\left(\lambda^{-1} \ln \mathrm{G}(\mathrm{x})\right), \quad \mathrm{x} \rightarrow \mathrm{c}_{+} .
$$

Moreover, let $\mathrm{d}=\sup _{\mathrm{x}} \operatorname{supp}(\mathrm{G})$, say; then, there holds true

$$
\mathrm{F}(\mathrm{x}) \sim \Phi\left(\lambda^{-1} \ln \overline{\mathrm{G}}(\mathrm{x})\right), \quad \mathrm{f}(\mathrm{x}) \sim \frac{\mathrm{g}(\mathrm{x})}{\lambda \overline{\mathrm{G}}(\mathrm{x})} \varphi\left(\lambda^{-1} \ln \overline{\mathrm{G}}(\mathrm{x})\right), \quad \mathrm{x} \rightarrow \mathrm{d}_{-} .
$$

We omit the straightforward proofs of these results, remarking that the asymptotic of the related hrf follows ad definitionem by the previous results for the cdf and pdf.

MOMENTS. Henceforth, let $\mathrm{Y}_{\ell+1} \sim \exp -\mathrm{G}(\ell+1), \ell \in \mathbb{N}_{0}$. The rth moment of $\mathrm{X}$ can be obtained from (7) and (20) as

$$
\mu_{\mathrm{r}}^{\prime}=\mathbb{E}\left(\mathrm{X}^{\mathrm{r}}\right)=\sum_{\ell \geq 0} \omega_{\ell} \mathbb{E}\left(\mathrm{Y}_{\ell+1}^{\mathrm{r}}\right)=\sum_{\ell \geq 0}(\ell+1) \omega_{\ell} \tau_{\mathrm{r}, \ell}
$$

where $\omega_{\ell}$ is given by (20) and

$$
\tau_{\mathrm{r}, \ell}=\int_{\mathbb{R}} \mathrm{x}^{\mathrm{r}} \mathrm{G}^{\ell}(\mathrm{x}) \mathrm{g}(\mathrm{x}) \mathrm{dx}=\int_{0}^{1} \mathrm{Q}_{\mathrm{G}}(\mathrm{u})^{\mathrm{r}} \mathrm{u}^{\ell} \mathrm{du} .
$$

The ordinary moments of several special LONG distributions can follow directly from (23). Further, the central moments and cumulants of $\mathrm{X}$ can be determined from the ordinary moments using well-known formulae. 
The rth incomplete moment of $\mathrm{X}$ is determined as

$$
m_{r}(y)=\int_{-\infty}^{y} x^{r} f(x) d x=\sum_{\ell \geq 0}(\ell+1) \omega_{\ell} \int_{0}^{G(y)} Q_{G}^{r}(u) u^{\ell} d u
$$

where the last integral can be evaluated at least numerically for most baseline $\mathrm{G}$ distributions.

The first incomplete moment $\mathrm{m}_{1}(\mathrm{y})$ plays an important role for measuring inequality such as the mean deviations and Lorenz and Bonferroni curves.

GENERATING FUNCTION. Here, we provide a formula for the moment generating function $(\mathrm{mgf}) \mathrm{M}(\mathrm{t})=$ $\mathbb{E}\left(\mathrm{e}^{\mathrm{t} X}\right)$ of $\mathrm{X}$. It follows from (7) that

$$
M(t)=\sum_{\ell=0}^{\infty} \omega_{\ell} M_{\ell+1}(t)=\sum_{\ell=0}^{\infty}(\ell+1) \omega_{\ell} \rho_{\ell}(t)
$$

where $\mathrm{M}_{\ell+1}(\mathrm{t})$ is the mgf of $\mathrm{Y}_{\ell+1}$ and

$$
\rho_{\ell}(t)=\int_{\mathbb{R}} e^{t x} G^{\ell}(x) g(x) d x=\int_{0}^{1} e^{t Q_{G}(u)} u^{\ell} d u
$$

can be evaluated at least numerically for most baseline models.

We can obtain the mgfs of several special LONG distributions directly from both equations in (25). ESTIMATION. Inference can be carried out in three different ways: point estimation, interval estimation and hypothesis tests. Several approaches for parameter point estimation were proposed in the literature but the maximum likelihood method is the most commonly employed. The maximum likelihood estimates (MLEs) enjoy desirable properties that can be used when constructing confidence intervals for the model parameters. Large sample theory for these estimates delivers simple approximations that work well in finite samples. The normal approximation for the MLE in distribution theory is easily handled either analytically or numerically.

Here, we consider the estimation of the unknown parameters of the new distribution by the maximum likelihood method. Let $\mathrm{x}_{1}, \ldots, \mathrm{x}_{\mathrm{n}}$ be $\mathrm{n}$ observed values from the LONG family of distribution given by (7)with vector of parameters $\Theta=(\lambda, \xi)^{\mathrm{T}}$. The log-likelihood function $\ell(\Theta)$ related to the parameter vector $\Theta$ becomes

$$
\ell(\Theta)=-\frac{n}{2} \ln \left(2 \pi \lambda^{2}\right)+\sum_{j=1}^{n} \ln g\left(x_{j}\right)-\sum_{j=1}^{n} \ln G\left(x_{j}\right) \bar{G}\left(x_{j}\right)-\frac{1}{2 \lambda^{2}} \sum_{j=1}^{n} \ln ^{2} \frac{G\left(x_{j}\right)}{\bar{G}\left(x_{j}\right)},
$$

where $\mathrm{g}\left(\mathrm{x}_{\mathrm{j}}\right):=\mathrm{g}\left(\mathrm{x}_{\mathrm{j}} ; \xi\right)$ and $\mathrm{G}\left(\mathrm{x}_{\mathrm{j}}\right):=\mathrm{G}\left(\mathrm{x}_{\mathrm{j}} ; \xi\right)$ by convention. The function $\ell(\Theta)$ can be maximized either directly by using well-known platforms such as the R (optim function), SAS (PROC NLMIXED), Ox program (MaxBFGS sub-routine) or by solving the nonlinear likelihood equations obtained by differentiation.

The compactness of the parameter space $\Theta$ and the continuity of the likelihood function on $\Theta$ are sufficient for the existence of the MLE. Also, if this parameter space is convex and the likelihood function is strictly concave in the model parameters, then the MLE is unique when it exists. General conclusions about these items depend on the nature of the parameter space which is related to the baseline distribution G. In fact, we do not need the third derivative of the log-likelihood function (as it is assumed by Cramér's theorem regarding asymptotic of the MLE) with respect to the parameter as stated by Theorem II in Gurland (1954) which guarantees the existence of a solution of the likelihood equation, being in the same time a consistent estimator of the involved parameter requiring derivatives only of second order. The MLE solution remains in the same time asymptotical normal and efficient. The LONG cdf given by (6) is assumed to be twice 
differentiable with respect to the variable x. However, for the Gurland's conditions, it should be three times differentiable with respect to the parameter vector $\Theta$. Since $\ell(\Theta)$ is composite function built by three times differentiable function G, Gurland's conditions are satisfied. So, the regularity and the existence of MLE with desired properties follow.

The components of the score vector $\mathrm{U}(\Theta)$ are given by

$$
\begin{aligned}
U_{\lambda}= & -\frac{n}{\lambda}+\frac{1}{\lambda^{3}} \sum_{j=1}^{n} \ln ^{2} \frac{G\left(x_{j}\right)}{\bar{G}\left(x_{j}\right)}, \\
U_{\xi}= & \sum_{j=1}^{n}\left[\frac{g^{(\xi)}\left(x_{j}\right)}{g\left(x_{j}\right)}-\frac{G^{(\xi)}\left(x_{j}\right)}{G\left(x_{j}\right)}-\frac{\bar{G}^{(\xi)}\left(x_{j}\right)}{\bar{G}\left(x_{j}\right)}\right] \\
& -\frac{1}{\lambda^{2}} \sum_{j=1}^{n} \frac{g\left(x_{j}\right)}{G\left(x_{j}\right) \bar{G}^{2}\left(x_{j}\right)} \ln \frac{G^{(\xi)}\left(x_{j}\right)}{\bar{G}\left(x_{j}\right)}\left\{G\left(x_{j}\right) \bar{G}^{2}\left(x_{j}\right) g(\xi)\left(x_{j}\right)+g\left(x_{j}\right) \bar{G}\left(x_{j}\right) G^{(\xi)}\left(x_{j}\right)\left[3 G\left(x_{j}\right)-1\right]\right\},
\end{aligned}
$$

where $\varphi^{(\xi)}(\cdot)$ denotes the derivative of the function $\varphi$ with respect to $\xi$. Setting $U_{\lambda}$ and $U_{\xi}$ equal to zero and solving the equations simultaneously yield the MLE $\widehat{\Theta}=(\widehat{\lambda}, \widehat{\xi})^{\mathrm{T}}$.

Under general regularity conditions $\sqrt{\mathrm{n}}(\widehat{\Theta}-\Theta) \stackrel{\mathrm{a}}{\sim} \mathrm{N}_{2}\left(0, \mathrm{~K}(\Theta)^{-1}\right)$, where $\mathrm{K}(\Theta)$ is the $2 \times 2$ expected information matrix and $\stackrel{a}{\sim}$ denotes asymptotic distribution. For $n$ large, $\mathrm{K}(\Theta)$ can be approximated by the observed information matrix. This normal approximation for the MLE $\widehat{\Theta}$ can be used for construing approximate confidence intervals for the parameters a and $\xi$. Likelihood ratio statistics can be adopted in the usual way for testing hypotheses on these parameters.

\section{LONG POWER-CAUCHY DISTRIBUTION AND ITS PROPERTIES}

Rooks et al. (2010) introduced a two-parameter power-Cauchy (PC) distribution. The rv Z has the PC distribution when the associated cdf and pdf are given by

$$
\mathrm{G}_{\mathrm{PC}}(\mathrm{x})=\mathrm{G}_{\mathrm{PC}}(\mathrm{x} ; \alpha, \sigma)=\frac{2}{\pi} \tan ^{-1}\left(\frac{\mathrm{x}}{\sigma}\right)^{\alpha} 1_{\mathbb{R}_{+}}(\mathrm{x})
$$

and

$$
\mathrm{g}_{\mathrm{PC}}(\mathrm{x})=\mathrm{g}_{\mathrm{PC}}(\mathrm{x} ; \alpha, \sigma)=\frac{2}{\pi}\left(\frac{\alpha}{\sigma}\right)\left(\frac{\mathrm{x}}{\sigma}\right)^{\alpha-1}\left[1+\left(\frac{\mathrm{x}}{\sigma}\right)^{2 \alpha}\right]^{-1} 1_{\mathbb{R}_{+}}(\mathrm{x}),
$$

respectively, where $\alpha>0$ is the shape parameter and $\varsigma>0$ the scale parameter. We will write this correspondence $\mathrm{Z} \sim \operatorname{PC}(\alpha, \sigma)$ in the sequel.

From (6), (7), (26) and (27), the LONPC cdf is given by

$$
\mathrm{F}(\mathrm{x})=\mathrm{F}(\mathrm{x} ; \alpha, \sigma, \lambda)=\frac{1}{2}\left[1+\operatorname{erf}\left(\frac{1}{\lambda \sqrt{2}} \ln \frac{\frac{2}{\pi} \tan ^{-1}\left(\frac{\mathrm{x}}{\sigma}\right)^{\alpha}}{1-\frac{2}{\pi} \tan ^{-1}\left(\frac{\mathrm{x}}{\sigma}\right)^{\alpha}}\right)\right] 1_{\mathbb{R}_{+}}(\mathrm{x}) .
$$

The related pdf is equal to

$$
\mathrm{f}(\mathrm{x})=\frac{\alpha\left(\frac{\mathrm{x}}{\sigma}\right)^{\alpha-1}}{\lambda \sigma \sqrt{2 \pi}\left[1+\left(\frac{\mathrm{x}}{\sigma}\right)^{2 \alpha}\right] \tan ^{-1}\left(\frac{\mathrm{x}}{\sigma}\right)^{2 \alpha}\left[1-\frac{2}{\pi} \tan ^{-1}\left(\frac{\mathrm{x}}{\sigma}\right)^{\alpha}\right]} \exp \left[-\frac{1}{2 \lambda^{2}} \ln ^{2} \frac{\frac{2}{\pi} \tan ^{-1}\left(\frac{\mathrm{x}}{\sigma}\right)^{\alpha}}{1-\frac{2}{\pi} \tan ^{-1}\left(\frac{\mathrm{x}}{\sigma}\right)^{\alpha}}\right] 1_{\mathbb{R}_{+}}(\mathrm{x}) .
$$


Henceforth, a random variable having pdf (29) is denoted by $\mathrm{X} \sim \operatorname{LONPC}(\lambda, \alpha, \sigma)$.

Note. For $\alpha=1$ the equation (29) reduces to the log-odd-normal half-Cauchy (LONHC) distribution not known in literature yet.

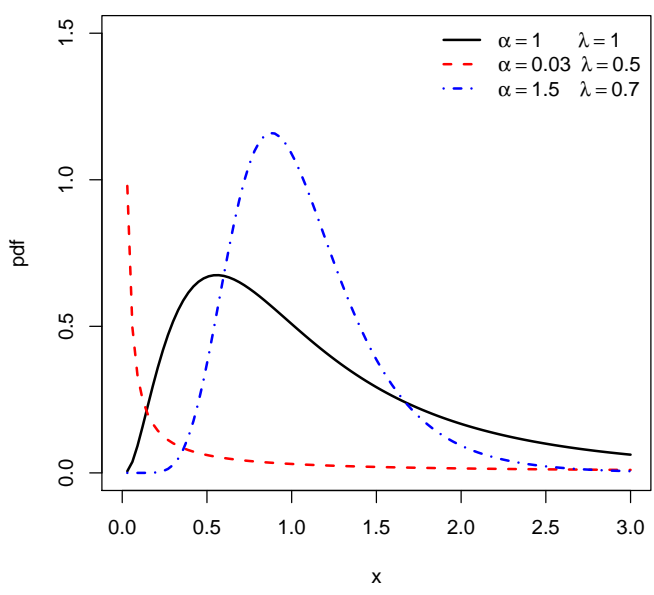

(a)

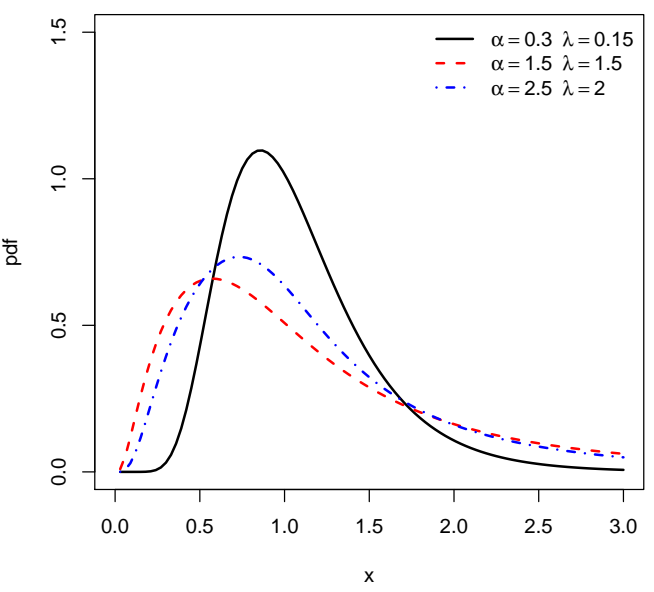

(b)

Figure 1 - Plots of the LONPC density for some values of $\lambda$ and $\alpha$.

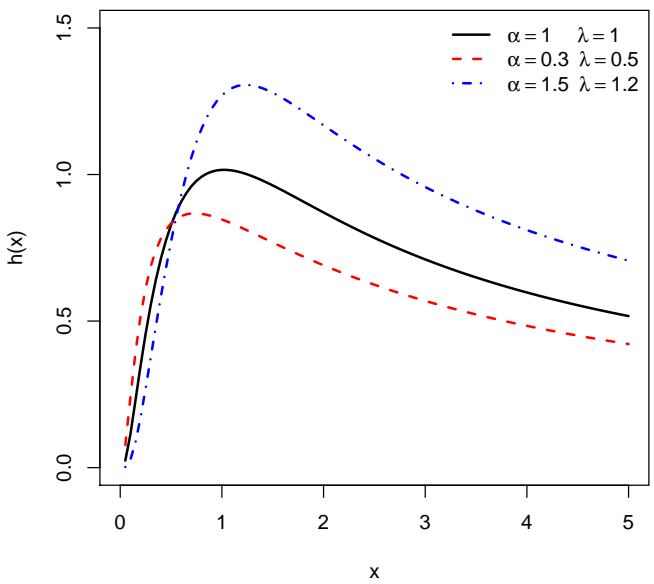

(a)

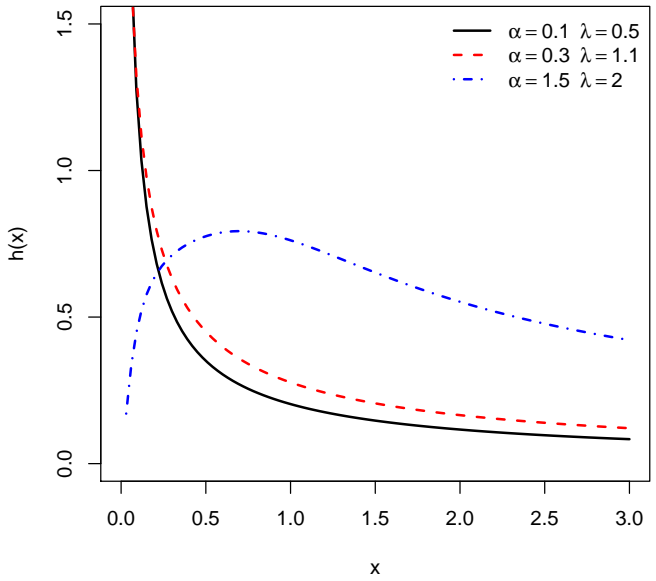

(b)

Figure 2 - Plots of the LONPC hazard rate for some values of $\lambda$ and $\alpha$.

Figures 1 and 2 display some plots of the density and hrf of X when $\sigma=1$ for different values of $\alpha$ and $\lambda$. The plots in Figure 1 reveal that the LONPC density produces only unimodal (right-skewed) shape. The plots in Figure 2 indicate that the hrf of X can have decreasing failure rate (DFR) and upside-down bathtub (UBT) shapes. 
The shapes of the density and hazard rate functions of X can be described analytically using the Theorem 5 which identifies the modality of the LONG distribution family. So, does the LONPC distribution family too. We recall now that

$$
y(1-y) y^{\prime \prime}=y^{\prime 2}\left(1-2 y+\frac{1}{\lambda^{2}} \ln \frac{y}{1-y}\right), \quad y:=F(x)
$$

i.e. the ordinary nonlinear second order differential equation covers the functional behavior of the $\operatorname{cdf} F(x)$ of the LONPC distribution given in (28) when we are looking for the saddle point of the pdf giving the mode of LONPC distributed rv X. The related hazard rate shape is a corollary of this result.

The asymptotics of the LONPC cdf and pdf follow the lines of previous LONG Proposition. We have the result.

Proposition 7. The cdf and the pdf of the rv X coming from the LONPC distribution possesses the following asymptotic behavior either when $\mathrm{x} \rightarrow 0$ and $\mathrm{x} \rightarrow \infty$ :

$$
\mathrm{F}(\mathrm{x}) \sim \Phi\left(\frac{2 \alpha}{\pi \lambda} \ln \frac{\mathrm{x}}{\sigma}\right), \quad \mathrm{f}(\mathrm{x}) \sim \frac{2 \alpha}{\pi \lambda \mathrm{x}} \varphi\left(\frac{2 \alpha}{\pi \lambda} \ln \frac{\mathrm{x}}{\sigma}\right)
$$

The proof is an immediate consequence of earlier LONG Proposition, the properties of the Laplace function $\Phi$ and the fact that the standard normal density is an even function. The asymptotic of the hazard rate function we can derive easily.

The $\mathrm{qf}$ of $\mathrm{X} \sim \operatorname{LONPC}(\alpha, \sigma, \lambda)$ is given by

$$
\mathrm{Q}(\mathrm{p})=\sigma\left\{\tan \left(\frac{\pi}{2} \frac{\exp \left[\lambda \sqrt{2} \operatorname{erf}^{-1}(2 \mathrm{p}-1)\right]}{1+\exp \left[\lambda \sqrt{2} \operatorname{erf}^{-1}(2 \mathrm{p}-1)\right]}\right)\right\}^{\frac{1}{\alpha}} 1_{(0,1)}(\mathrm{p}),
$$

where $\operatorname{erf}^{-1}(\mathrm{x})=\Phi^{-1}(\mathrm{z} / 2) / \sqrt{2}$ defines the inverse error function in terms of the qf of the normal distribution.

Let $\mathrm{T} \sim \mathrm{N}\left(0, \lambda^{2}\right)$. Based on second Lemma of LONG family, we obtain

$$
\mathrm{X}=\sigma\left[\tan \left(\frac{\pi}{2} \frac{\mathrm{e}^{\mathrm{T}}}{1+\mathrm{e}^{\mathrm{T}}}\right)\right]^{\frac{1}{\alpha}} \sim \operatorname{LONPC}(\lambda, \alpha, \sigma)
$$

For $\alpha=1$, we have $\mathrm{X} \sim \operatorname{LONHC}(\lambda, \sigma)$.

Theorem 8. The $\mathrm{r}$ th ordinary moment of $\mathrm{X} \sim \operatorname{LONPC}(\lambda, \alpha, \sigma)$ has the following form:

$$
\mathbb{E}\left(X^{r}\right)=\sigma^{r}(2 \pi)^{\frac{r}{\alpha}} \sum_{n \geq 0} \kappa_{n}(r, \alpha) e^{\lambda^{2} n^{2}}
$$


where $\kappa_{\mathrm{n}}(\mathrm{r}, \alpha)$ is defined by the coefficients chain

$$
\begin{aligned}
a_{j} & =\frac{(-1)^{j} \pi^{2 j}\left(4^{j+1}-1\right) B_{2 j+2}}{(2 j+2) !}, \quad j \in \mathbb{N}_{0}, \\
b_{k} & =\sum_{n=1}^{k}\left(\begin{array}{l}
\frac{r}{\alpha} \\
n
\end{array}\right) n c_{k}, \quad b_{0}=1, \\
n c_{k} & = \begin{cases}\sum_{\substack{0 \leq n_{1}, n_{2}, \cdots, n_{k} \leq n \\
n_{1}+n_{2}+\cdots+n_{k}=n \\
n_{1}+2 n_{2}+\cdots+k_{k}=k}} n ! \prod_{j=1}^{k} \frac{a_{j}}{\prod_{j} n_{j} !}, \\
\frac{B(k, n)}{(k-n) !}, & m=0,\end{cases} \\
\kappa_{m}(r, \alpha) & = \begin{cases}1, & m \in \mathbb{N}, \\
\sum_{j=1}^{m}\left[(2 k+2) \frac{j}{m}-1\right] b_{m-j}, & \end{cases}
\end{aligned}
$$

where $B_{\ell}$ stands for the Bernoulli number of the order $\ell \in \mathbb{N}$.

Proof. We have ad definitionem with the aid of (10)

$$
\mathbb{E}\left(\mathrm{X}^{\mathrm{r}}\right)=\frac{\sigma^{\mathrm{r}}}{\lambda \sqrt{2 \pi}} \int_{\mathbb{R}}\left[\tan \left(\frac{\pi}{2} \frac{\mathrm{e}^{\mathrm{t}}}{1+\mathrm{e}^{\mathrm{t}}}\right)\right]^{\frac{\mathrm{r}}{\alpha}} \exp \left(-\frac{\mathrm{t}^{2}}{2 \lambda^{2}}\right) \mathrm{dt} .
$$

The Maclaurin series of the function $\tan (\mathrm{x})$ reads Abramowitz and Stegun (1972, p. 75; Eq. 4.3.67)

$$
\tan (x)=x \sum_{n \geq 0} \frac{(-1)^{n} 4^{n+1}\left(4^{n+1}-1\right) B_{2 n+2}}{(2 n+2) !} x^{2 n}, \quad|x|<\frac{\pi}{2},
$$

where $B_{2 n}$ denotes the Bernoulli number of the order 2 n. Hence,

$$
\begin{aligned}
S^{\frac{r}{\alpha}}(t) & =\left[\tan \left(\frac{\pi}{2} \frac{e^{t}}{1+e^{t}}\right)\right]^{\frac{r}{\alpha}} \\
& =\left[2 \pi \sum_{n \geq 0} \frac{(-1)^{n} \pi^{2 n}\left(4^{n+1}-1\right) B_{2 n+2}}{(2 n+2) !}\left(\frac{e^{t}}{1+e^{t}}\right)^{2 n+1}\right]^{\frac{r}{\alpha}},
\end{aligned}
$$

for all real $\mathrm{t}$ as $|\mathrm{x}|=\frac{\pi}{2}\left(1+\mathrm{e}^{-\mathrm{t}}\right)^{-1}<\frac{\pi}{2}$ is in accordance with (33). The power series $\mathrm{S}$ raised by real power $\mathrm{r} / \alpha$ (see Appendix B) gives

$$
S^{\frac{r}{\alpha}}(t)=\left(\frac{2 \pi e^{t}}{1+e^{t}}\right)^{\frac{r}{\alpha}} \sum_{k \geq 0} b_{k}\left(\frac{e^{t}}{1+e^{t}}\right)^{2 k}
$$

where according to (43)

$$
b_{k}=\sum_{n=1}^{k}\left(\begin{array}{l}
\mu \\
n
\end{array}\right) \sum_{(n)} n ! \prod_{j=1}^{k} \frac{a_{j}^{n_{j}}}{\prod_{j} n_{j} !}, \quad a_{j}=\frac{(-1)^{j} \pi^{2 j}\left(4^{j+1}-1\right) B_{2 j+2}}{(2 j+2) !} .
$$


Next,

$$
\mathrm{S}^{\frac{\mathrm{r}}{\alpha}}(\mathrm{t})=(2 \pi)^{\frac{\mathrm{r}}{\alpha}} \sum_{\mathrm{k} \geq 0} \mathrm{~b}_{\mathrm{k}}\left[\sum_{\mathrm{n} \geq 0}\left(\begin{array}{l}
\frac{\mathrm{r}}{\alpha} \\
\mathrm{n}
\end{array}\right) \mathrm{e}^{-\mathrm{nt}}\right]^{2 \mathrm{k}+1} .
$$

By repeating once more the whole procedure of the odd integer power of a power series reported in Appendix B combined with the multiplication of two similar structure power series, we obtain

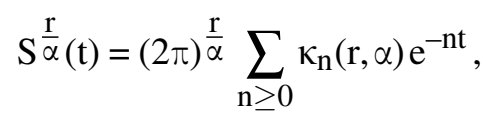

where the coefficients $\kappa_{\mathrm{n}}(\mathrm{r}, \alpha)$ can be obtained recursively.

Now, in establishing the computational series expansion result (31) in treating the integral expression (32) of

$$
\mathbb{E}\left(X^{r}\right)=\sigma^{r} \int_{\mathbb{R}} S^{\frac{r}{\alpha}}(t) \exp \left(-\frac{t^{2}}{2 \lambda^{2}}\right) d t
$$

it remains to establish the value of the constituting integral, viz.

$$
\begin{aligned}
\mathbb{E}\left(X^{r}\right) & =\frac{\sigma^{r}(2 \pi)^{\frac{\mathrm{r}}{\alpha}-\frac{1}{2}}}{\lambda} \sum_{n \geq 0} \kappa_{n}(r, \alpha) \int_{\mathbb{R}} \exp \left(-n t-\frac{t^{2}}{2 \lambda^{2}}\right) d t \\
& =\sigma^{r}(2 \pi)^{\frac{r}{\alpha}} \sum_{n \geq 0} \kappa_{n}(r, \alpha) e^{\lambda^{2} n^{2}},
\end{aligned}
$$

which proves the assertion.

The rth ordinary moment of the LONPC distribution can be determined from (23). The ordinary and incomplete moments of the exponentiated-PC (exp-PC) with power parameter $(\ell+1)$ can follow from the procedure used in (Tahir et al. 2016) and the power series

$$
[\tan (\mathrm{x})]^{\mathrm{s}}=\sum_{\mathrm{i}=0}^{\infty} \mathrm{a}_{\mathrm{i}}(\mathrm{s}) \mathrm{x}^{2 \mathrm{i}+\mathrm{s}},
$$

where $\mathrm{a}_{0}(\mathrm{~s})=1, \mathrm{a}_{1}(\mathrm{~s})=\mathrm{s} / 3, \mathrm{a}_{2}(\mathrm{~s})=\mathrm{s}(5 \mathrm{~s}+7) / 90$, etc.

After some algebra, an alternative expression for the rth moment of $\mathrm{X}$ based on the $\operatorname{PC}(\alpha, \sigma)$ rv can be expressed as

$$
\mathbb{E}\left(X^{\mathrm{r}}\right)=\sigma^{\mathrm{r}}\left(\frac{\pi}{2}\right)^{\frac{\mathrm{r}}{\alpha}} \sum_{\mathrm{k}, \ell \geq 0} \frac{(\ell+1) \omega_{\ell}\left(\frac{\pi}{2}\right)^{2 \mathrm{k}} \mathrm{a}_{\mathrm{k}}\left(\frac{\mathrm{r}}{\alpha}\right)}{\left(\ell+2 \mathrm{k}+\frac{\mathrm{r}}{\alpha}+1\right)},
$$

where $\mathrm{a}_{\mathrm{k}}\left(\frac{\mathrm{s}}{\alpha}\right), \mathrm{k} \in \mathbb{N}_{0}$, is obtained from (36).

From Equation (24), the rth incomplete moment of $\mathrm{X}$ is given by

$$
\mathrm{m}_{\mathrm{r}}^{\prime}(\mathrm{y})=\sigma^{\mathrm{r}}\left(\frac{\pi}{2}\right)^{\frac{\mathrm{r}}{\alpha}} \mathrm{z}^{\frac{\mathrm{r}}{\alpha}+1}(\mathrm{y}) \sum_{\mathrm{k}, \ell \geq 0} \frac{(\ell+1) \omega_{\ell}\left(\frac{\pi}{2}\right)^{2 \mathrm{k}} \mathrm{a}_{\mathrm{k}}\left(\frac{\mathrm{r}}{\alpha}\right) \mathrm{z}^{\ell+2 \mathrm{k}}(\mathrm{y})}{\left(\ell+2 \mathrm{k}+\frac{\mathrm{r}}{\alpha}+1\right)},
$$

where $\mathrm{z}(\mathrm{y})=\frac{2}{\pi} \tan ^{-1}\left(\frac{\mathrm{y}}{\sigma}\right)^{\alpha}$.

Tahir et al. (2016, Sect. 6.10) obtained the mgf of the EPC distribution using exponential partial Bell polynomials given by

$$
\mathrm{B}_{\mathrm{s}, \mathrm{k}}=\mathrm{B}_{\mathrm{s}, \mathrm{k}}\left(\mathrm{x}_{1}, \ldots, \mathrm{x}_{\mathrm{s}-\mathrm{k}+1}\right)=\sum \frac{\mathrm{s} !}{\mathrm{c}_{1} ! \mathrm{c}_{2} ! \ldots(1 !)^{\mathrm{c}_{1}(2 !)^{\mathrm{c}_{2}} \ldots}} \mathrm{x}_{1}^{\mathrm{c}_{1}} \mathrm{x}_{2}^{\mathrm{c}_{2}} \ldots
$$


where the sum varies over all integers $c_{1}, c_{2}, \ldots \geq 0$ such that $c_{1}+2 c_{2}+3 c_{3}+\cdots=s$ and $c_{1}+c_{2}+c_{3}+\cdots=k$. These polynomials can be evaluated in MaTHEMATICA and MAPLE.

They demonstrated that the mgf of $\mathrm{Y}_{\mathrm{a}}$, say $\mathrm{M}_{\mathrm{a}}(\mathrm{t})$, can be expressed as

$$
\mathrm{M}_{\mathrm{a}}(\mathrm{t})=\mathrm{a} \sum_{\mathrm{s}, \mathrm{k}, \mathrm{r} \geq 0} \frac{(\sigma \mathrm{t})^{\mathrm{r}+\mathrm{k}}\left[(0.5 \pi)^{1 / \alpha} \mathrm{a}_{0}\left(\alpha^{-1}\right)\right]^{\mathrm{r}} \mathrm{B}_{\mathrm{s}, \mathrm{k}}}{[\mathrm{a}+(\mathrm{k}+\mathrm{r}) / \alpha] \mathrm{r} ! \mathrm{k} !},
$$

where $d_{i}\left(\alpha^{-1}\right)=i !(0.5 \pi)^{2 i+\alpha^{-1}} a_{i}\left(\alpha^{-1}\right), a_{i}\left(\alpha^{-1}\right)$ comes from Equation (36) and, for $\mathrm{i} \geq 1$ while, $\mathrm{B}_{\mathrm{s}, \mathrm{k}}=\mathrm{B}_{\mathrm{s}, \mathrm{k}}\left(\mathrm{d}_{1}\left(\alpha^{-1}\right), \ldots, \mathrm{d}_{\mathrm{s}-\mathrm{k}+1}\left(\alpha^{-1}\right)\right)$.

Then, the mgf of $\mathrm{X}$ follows from Equation (25) as

$$
\mathrm{M}(\mathrm{t})=\sum_{\ell=0}^{\infty} \omega_{\ell} \mathrm{M}_{\ell+1}(\mathrm{t})
$$

where $\mathbf{M}_{\ell+1}(\mathrm{t})$ can be determined from Equation (37).

The estimation of the unknown parameters of the LONPC distribution is dealt by the maximum likelihood method. Let $\mathrm{x}_{1}, \cdots, \mathrm{x}_{\mathrm{n}}$ be $\mathrm{n}$ observed values from the LONPC distribution given by (29) with vector of parameters $\vartheta=(\alpha, \sigma, \lambda)^{\mathrm{T}}$. The log-likelihood $\ell(\vartheta)$ for $\vartheta$ is given by

$$
\begin{aligned}
\ell(\vartheta)= & n \ln \frac{\alpha}{\lambda \sigma \sqrt{2 \pi}}+(\alpha-1) \sum_{i=1}^{n} \ln \left(\frac{x_{i}}{\sigma}\right)-\sum_{i=1}^{n} \ln \left(\frac{\pi z_{i}}{2}\right)-\sum_{i=1}^{n} \ln \left[1+\left(\frac{x_{i}}{\sigma}\right)^{2 \alpha}\right] \\
& -\sum_{i=1}^{n} \ln \left(1-z_{i}\right)-\frac{1}{2 \lambda^{2}} \sum_{i=1}^{n} \ln ^{2} \frac{z_{i}}{1-z_{i}},
\end{aligned}
$$

where $z_{i}=\frac{2}{\pi} \tan ^{-1}\left(\frac{x_{i}}{\sigma}\right)^{\alpha}$.

The MLE $\widehat{\vartheta}$ of $\vartheta$ can be obtained by maximizing the log-likelihood function $\ell(\vartheta)$ with respect to $\vartheta$. There are several routines available for numerical maximization of (38) given in the $\mathrm{R}$ program (optim function), SAS (PROC NLMIXED), Ox (sub-routine MaxBFGS). Alternatively, we can differentiating (38) and solving the resulting nonlinear likelihood equations.

The partial derivatives of $\ell(\vartheta)$ with respect to the parameters are given by

$$
\begin{aligned}
\frac{\partial \ell(\vartheta)}{\partial \alpha}= & \frac{\mathrm{n}}{\alpha}+\sum_{\mathrm{i}=1}^{\mathrm{n}} \ln \frac{\mathrm{x}_{\mathrm{i}}}{\sigma}+\frac{\sigma}{\alpha} \sum_{\mathrm{i}=1}^{\mathrm{n}} \frac{\mathrm{z}_{\mathrm{i} \sigma}^{\prime}}{\mathrm{z}_{\mathrm{i}}} \ln \frac{\mathrm{x}_{\mathrm{i}}}{\sigma}+\frac{\pi}{\alpha \sigma^{\alpha-1}} \sum_{\mathrm{i}=1}^{\mathrm{n}} \mathrm{z}_{\mathrm{i} \sigma}^{\prime} \mathrm{x}_{\mathrm{i}}^{\alpha} \ln \left(\frac{\mathrm{x}_{\mathrm{i}}}{\sigma}\right)-\frac{2}{\alpha \sigma^{\alpha-1}} \sum_{\mathrm{i}=1}^{\mathrm{n}} \frac{\mathrm{z}_{\mathrm{i} \sigma}^{\prime}}{1-\mathrm{z}_{\mathrm{i}}} \mathrm{x}_{\mathrm{i}}^{\alpha} \ln \left(\frac{\mathrm{x}_{\mathrm{i}}}{\sigma}\right) \\
& +\frac{2}{\alpha \lambda^{2} \sigma^{\alpha-1}} \sum_{\mathrm{i}=1}^{\mathrm{n}} \frac{\mathrm{z}_{\mathrm{i} \sigma}^{\prime} \mathrm{x}_{\mathrm{i}}^{\alpha-1}\left(1-\mathrm{z}_{\mathrm{i}}\right)}{\mathrm{z}_{\mathrm{i}}} \ln \frac{\mathrm{z}_{\mathrm{i}}}{1-\mathrm{z}_{\mathrm{i}}} \ln \left(\frac{\mathrm{x}_{\mathrm{i}}}{\sigma}\right), \\
\frac{\partial \ell(\vartheta)}{\partial \sigma}= & -\frac{\mathrm{n} \alpha}{\sigma}-\sum_{\mathrm{i}=1}^{\mathrm{n}} \frac{\mathrm{z}_{\mathrm{i} \sigma}^{\prime}}{\mathrm{z}_{\mathrm{i}}}-\frac{\pi}{\sigma^{\alpha}} \sum_{\mathrm{i}=1}^{\mathrm{n}} \mathrm{z}_{\mathrm{i} \sigma}^{\prime} \mathrm{x}_{\mathrm{i}}^{\alpha}+\sum_{\mathrm{i}=1}^{\mathrm{n}} \frac{\mathrm{z}_{\mathrm{i} \sigma}^{\prime}}{1-\mathrm{z}_{\mathrm{i}}}-\frac{1}{\lambda^{2}} \sum_{\mathrm{i}=1}^{\mathrm{n}} \frac{\mathrm{z}_{\mathrm{i} \sigma}^{\prime}}{\mathrm{z}_{\mathrm{i}}\left(1-\mathrm{z}_{\mathrm{i}}\right)} \ln \frac{\mathrm{z}_{\mathrm{i}}}{1-\mathrm{z}_{\mathrm{i}}}, \\
\frac{\partial \ell(\vartheta)}{\partial \lambda=} & -\frac{\mathrm{n}}{\lambda}+\frac{1}{\lambda^{3}} \sum_{\mathrm{i}=1}^{\mathrm{n}} \ln ^{2} \frac{\mathrm{z}_{\mathrm{i}}}{1-\mathrm{z}_{\mathrm{i}}},
\end{aligned}
$$

where $\mathrm{z}_{\mathrm{i} \sigma}^{\prime}=-\frac{2 \alpha}{\pi \sigma}\left(\frac{\mathrm{x}_{\mathrm{i}}}{\sigma}\right)^{\alpha}\left[1+\left(\frac{\mathrm{x}_{\mathrm{i}}}{\sigma}\right)^{2 \alpha}\right]^{-1}$. 


\section{APPLICATION AS AN EMPIRICAL ILLUSTRATION OF LONG FAMILY}

In this section, we fit the LONPC model along with some other competing models to a real data set. We compare the goodness-of-fit of the LONPC model with the beta-half-Cauchy (BHC) (Cordeiro and Lemonte, 2011), Kumaraswamy half-Cauchy (KHC) (Ghosh, 2014), gamma half-Cauchy (GHC) (Alzaatreh et al. 2016), exponentiated half-Cauchy (EHC) and PC models. For each model, we estimate the parameters by using the method of maximum likelihood and adopt the Cramér-von Mises $\left(\mathrm{W}^{*}\right)$, Anderson-Darling $\left(\mathrm{A}^{*}\right)$ and Kolmogrov-Smirnov (K-S) statistics for model comparison purposes. In general, the smaller the values of these statistics, the better the fit to the data. The densities (for $x>0$ ) and parameters $(a, b, \beta, \varsigma>0)$ of the $\mathrm{BHC}, \mathrm{KHC}, \mathrm{GHC}$ and

EHC models are, respectively, given by

$$
\begin{aligned}
& \mathrm{f}_{\mathrm{BHC}}(\mathrm{x})=\frac{2^{\mathrm{a}}\left[\tan ^{-1}\left(\frac{\mathrm{x}}{\sigma}\right)\right]^{\mathrm{a}-1}}{\sigma \pi^{\mathrm{a}} \mathrm{B}(\mathrm{a}, \mathrm{b})\left(1+\left(\frac{\mathrm{x}}{\sigma}\right)^{2}\right)}\left[1-\frac{2}{\pi} \tan ^{-1}\left(\frac{\mathrm{x}}{\sigma}\right)\right]^{\mathrm{b}-1} 1_{\mathbb{R}_{+}}(\mathrm{x}), \\
& \mathrm{f}_{\mathrm{KHC}}(\mathrm{x})=\frac{\mathrm{ab} 2^{\mathrm{a}}\left[\tan ^{-1}\left(\frac{\mathrm{x}}{\sigma}\right)\right]^{\mathrm{a}-1}}{\sigma \pi^{\mathrm{a}}\left(1+\left(\frac{\mathrm{x}}{\sigma}\right)^{2}\right)}\left[1-\left\{\frac{2}{\pi} \tan ^{-1}\left(\frac{\mathrm{x}}{\sigma}\right)\right\}^{\mathrm{a}}\right]^{\mathrm{b}-1} 1_{\mathbb{R}_{+}}(\mathrm{x}), \\
& \mathrm{f}_{\mathrm{GHC}}(\mathrm{x})=\frac{2\left[1-\frac{2}{\pi} \tan ^{-1}\left(\frac{\mathrm{x}}{\sigma}\right)\right]^{\frac{1}{\beta}-1}}{\pi \sigma \Gamma(\alpha) \beta^{\alpha}\left(1+\left(\frac{\mathrm{x}}{\sigma}\right)^{2}\right)}\left(-\ln \left[1-\frac{2}{\pi} \tan ^{-1}(\mathrm{x} / \sigma)\right]\right)^{\alpha-1} 1_{\mathbb{R}_{+}}(\mathrm{x}), \\
& \mathrm{f}_{\mathrm{EHC}}(\mathrm{x})=\frac{\mathrm{a} 2^{\mathrm{a}}\left[\tan ^{-1}\left(\frac{\mathrm{x}}{\sigma}\right)\right]^{\mathrm{a}-1}}{\sigma \pi^{\mathrm{a}}\left(1+\left(\frac{\mathrm{x}}{\sigma}\right)^{2}\right)} 1_{\mathbb{R}_{+}}(\mathrm{x}) .
\end{aligned}
$$

The data set represents the results of a life testing experiment in which specimens of a type of electrical insulating fluid were subjected to a constant voltage stress. The length of time until each specimen failed or "broke down" was observed. Seven groups of specimens were tested at voltages ranging from 26 to 38 kilovolts (KV). More details about the data can be found in Nelson (1972). A summary of the data is: $n=76$, $\overline{\mathrm{X}}=98.55763, \mathrm{~s}=340.7395$, skewness $=5.14647$ and kurtosis $=27.29282$. The MLEs (with SEs in parentheses), $\mathrm{W}^{*}, \mathrm{~A}^{*}$ and K-S statistics are listed in Table I. The three goodness-of-fit statistics indicate that the LONPC model provides the best fit. The histogram of these data and the estimated pdfs of the LONPC distribution and its competitive models are displayed in Figure 3. It is clear from Table I that the LONPC model provides the best fit. Furthermore, the TTT plot of these data is shown in Figure 4a. It is convex, which suggests a decreasing failure rate. Figure $4 \mathrm{~b}$ displays the plot of the estimated LONPC hrf, which is in agreement with that TTT plot of Figure 4a.

\section{CONCLUSIONS}

We introduce and study a new wide log-odd normal generalized family of distributions and obtain some properties of a special model called the log-odd normal power-Cauchy distribution. We derive a linear representation for the family density in terms of exponentiated densities. Some structural properties of the new family and of its special distribution are determined including quantile and generating functions, ordinary and incomplete moments, asymptotics, among others. We estimate the model parameters by the 

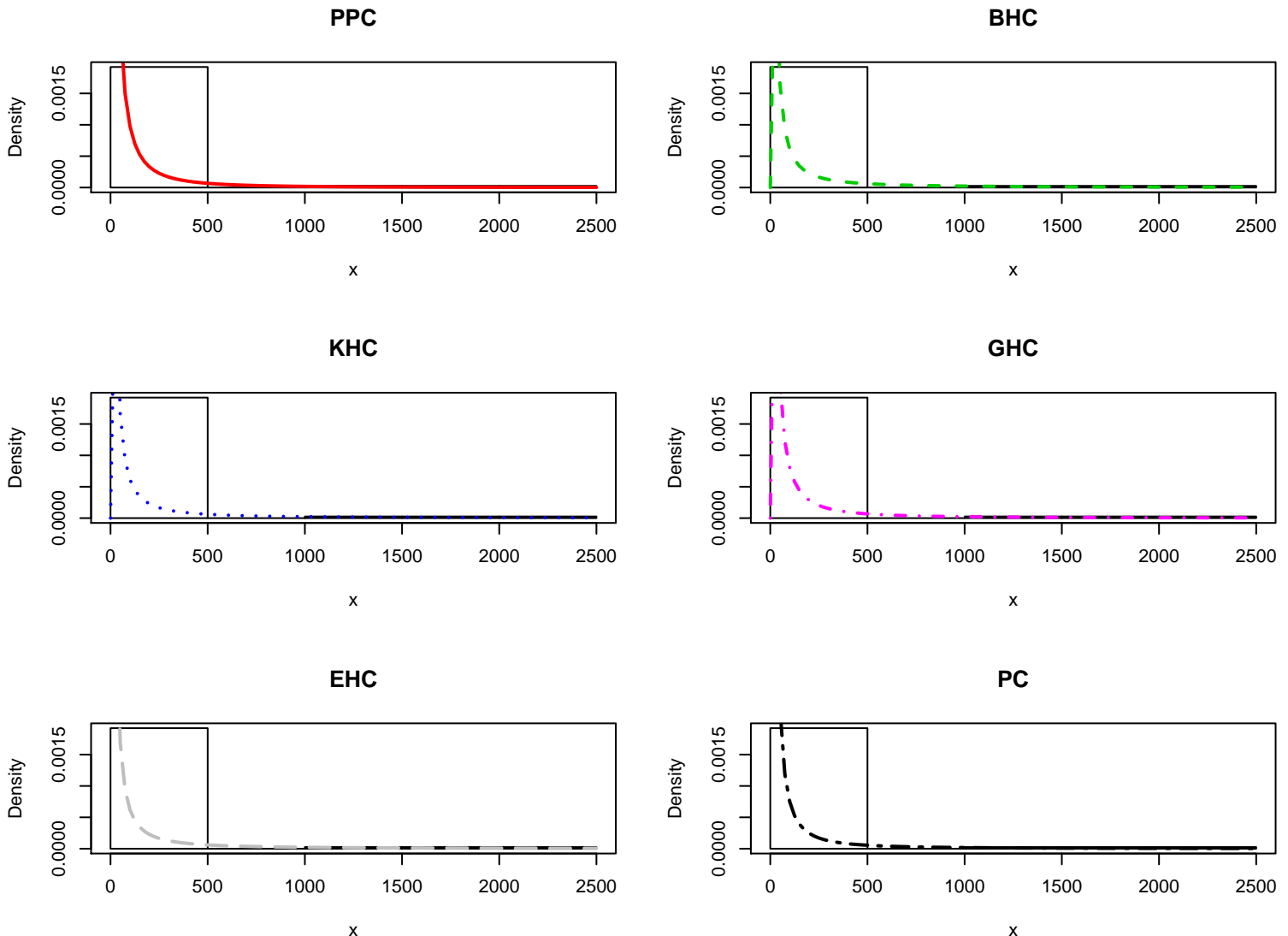

Figure 3 - Density plots of the LONPC, BHC, KHC, GHC, EHC and PC models for Failure data.

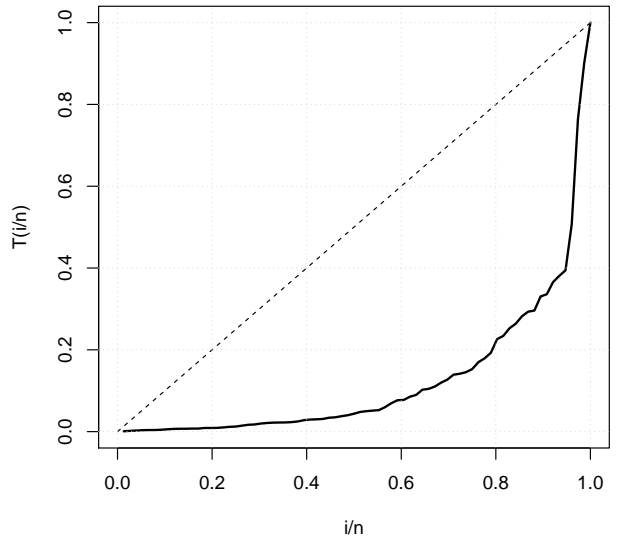

(a)

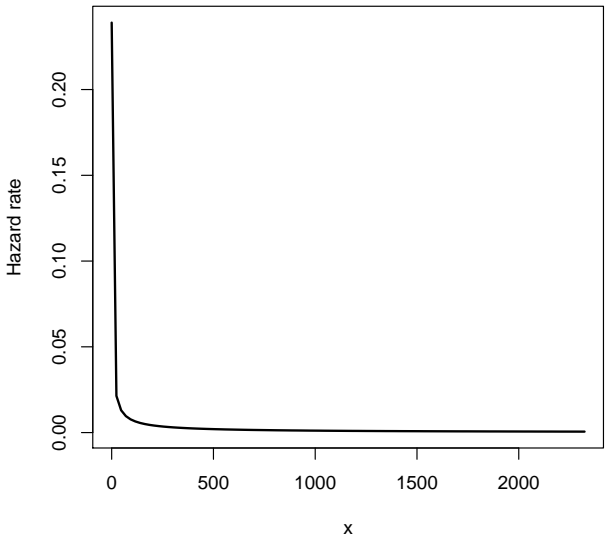

(b)

Figure 4 - (a) TTT plot, (b) estimated hrf of LONPC. 
TABLE I

MLEs, their SEs (in parentheses) and goodness-of-fit measures for the Failure data.

\begin{tabular}{|c|c|c|c|c|c|c|}
\hline Distribution & & Estimate & & $\mathrm{W}^{*}$ & $\mathrm{~A}^{*}$ & K-S \\
\hline \multirow[t]{2}{*}{$\operatorname{LONPC}(\alpha, \varsigma, \lambda)$} & 0.0396 & 0.1111 & 8.7254 & 0.0552 & 0.3591 & 0.0660 \\
\hline & $(0.0950)$ & $(0.2665)$ & (2.2338) & & & \\
\hline \multirow[t]{2}{*}{$\mathrm{BHC}(\mathrm{a}, \mathrm{b}, \varsigma)$} & 1.2127 & 0.4307 & 1.3306 & 0.1111 & 0.7045 & 0.0891 \\
\hline & $(0.6451)$ & $(0.0785)$ & (1.3117) & & & \\
\hline \multirow[t]{2}{*}{$\mathrm{KHC}(\mathrm{a}, \mathrm{b}, \varsigma)$} & 1.1680 & 0.4357 & 1.5271 & 0.1091 & 0.6949 & 0.0855 \\
\hline & $(0.7803)$ & $(0.0918)$ & $(1.7355)$ & & & \\
\hline \multirow[t]{2}{*}{$\operatorname{GHC}(\alpha, \beta, \varsigma)$} & 8.7637 & 0.7655 & 0.0160 & 0.0692 & 0.4927 & 0.0814 \\
\hline & (4.0796) & $(0.1758)$ & $(0.0118)$ & & & \\
\hline \multirow[t]{2}{*}{$\operatorname{EHC}(a, \varsigma)$} & 2.2433 & 1.8786 & & 0.1032 & 0.6635 & 0.0867 \\
\hline & $(0.3687)$ & $(0.6468)$ & & & & \\
\hline \multirow[t]{2}{*}{$\operatorname{PC}(\alpha, \varsigma)$} & 0.6426 & 7.5450 & & 0.1057 & 0.6537 & 0.0699 \\
\hline & $(0.0654)$ & $(2.0126)$ & & & & \\
\hline
\end{tabular}

maximum likelihood method. We compare the performance of the new distribution with other related distributions by means of a real air pollution data set using classical goodness-of-fit statistics.

\section{ACKNOWLEDGMENTS}

The authors wish to thank the two referees for their valuable comments which led to improvement in the earlier version of the article.

\section{AUTHOR CONTRIBUTIONS}

The first author (MZ) introduced the idea and obtained main properties of the family and the special case. The second author (TKP) developed some important mathematical properties including the modality analysis study. The third author (GMC) obtained linear representation and helped in developing properties. The last author (MHT) wrote the introduction section and worked on the application section. All authors together refined the manuscript with consultation to each other.

\section{REFERENCES}

ABRAMOWITZ M AND STEGUN IA. 1972. Handbook of Mathematical Functions with Formulas, Graphs, and Mathematical Tables. Applied Mathematics Series 55, National Bureau of Standards, Washington, D. C., $9^{\text {th }}$ Reprinted ed. New York: Dover Publications.

AL-AQTASH R, FAMOYE F AND LEE C. 2015. On generating a new family of distributions using the logit function. J Probab Stat Sci 13: 135-152.

AL-AQTASH R, LEE C AND FAMOYE F. 2014. Gumbel-Weibull distribution: Properties and applications. J Mod Appl Stat Methods 13: 201-225. 
ALEXANDER C., CORDEIRO GM, ORTEGA EMM AND SARABIA JM. 2012. Generalized beta-generated distributions. Comput Stat Data Anal 56: 1880-1897.

ALIZADEH M, CORDEIRO GM, NASCIMENTO ADC, LIMA MCS AND ORTEGA EMM. 201). Odd-Burr generalized family of distributions with some applications. J Stat Comput Simul 87: 367-389.

ALZAATREH A, FAMOYE F AND LEE C. 2013. A new method for generating families of continuous distributions. Metron 71: 63-79.

ALZAATREH A, FAMOYE F AND LEE C. 2014a. The gamma-normal distribution: Properties and applications. Comput Stat Data Anal 69: 67-80.

ALZAATREH A, FAMOYE F AND LEE C. 2014b. T-normal family of distributions: A new approach to generalize the normal distribution. J Stat Dist Applic 1: Art 16.

ALZAATREH A, MANSOOR M, TAHIR MH, ZUBAIR M AND GHAZALI SSA. 2016. The gamma half-Cauchy distribution: properties and applications. Hacet J Math Stat 45: 1143-1159.

AZZALINI A. 1985. A class of distributions which includes the normal ones. Scand J Statist 12: 171-178.

BARGA AS, CORDEIRO GM, ORTEGA EMM AND da-CRUZ JN. 2016. The odd log-logistic normal distribution: Theory and applications. J Stat Theory Prac 10: 311-335.

BOURGUIGNON M, SILVA RB AND CORDEIRO GM 2014. The Weibull-G family of probability distributions. J Data Sci 12 : 53-68.

COMTET L. 1974. Advanced Combinatorics. The art of finite and infinite expansions. Revised and enlarged edition. Dordrecht: D. Reidel Pubishing Corporation.

COORAY K AND ANANDA MMA 2008. A generalization of the half-normal distribution with applications to lifetime data. Commun Stat Theory Methods 37: 1323-1337.

CORDEIRO GM, ALIZADEH M, RAMIRES TG AND ORTEGA EEM. 2017. The generalized odd half-Cauchy family of distributions: Properties and applications. Commun Stat Theory Methods 46: 5685-5705.

CORDEIRO GM, CINTRA RJ, RĜO LC AND ORTEGA EEM 2012. The McDonald normal distribution. Pak J Stat Oper Res 8: 301-329.

CORDEIRO GM AND DE-CASTRO M. 2011. A new family of generalized distributions. J Stat Comput Simul 81: 883-893.

CORDEIRO GM AND LEMONTE AJ. 2011. The beta-half-Cauchy distribution. J Probab Statist ArtID-904705: 18 p.

CORREA MA, NOGUEIRA DA AND FERREIRA EB. 2012. Kumaraswamy Normal and Azzalini's skew Normal modeling asymmetry. Sigmae 1: 65-83.

EUGENE N, LEE C AND FAMOYE F. 2002. Beta-normal distribution and its applications. Commun Stat Theory Methods 31: 497-512.

FAMOYE F, LEE C AND EUGENE N. 2004. Beta-normal Distribution: Bimodality properties and application. J Mod Appl Stat Methods 3: 85-103.

GHOSH I. 2014. The Kumaraswamy-half Cauchy distribution: Properties and applications. J Stat Theory Applic 13: 122-134.

GLEATON JU AND LYNCH JD. 2006. Properties of generalized log-logistic families of lifetime distributions. J Probab Stat Sci 4: 51-64.

GRADSHTEYN IS AND RYZHIK IM. 2000. Table of Integrals, Series and Products. $6^{\text {th }}$ ed. San Diego: Academic Press.

GUI W, CHEN P-C AND WU H. 2013. A folded normal slash distribution and its applications to non-negative measurements. J Data Sci 11: 231-247.

GÜRLAND J. 1954. On regularity conditions for maximum likelihood estimators. Scand Actuarial J 1: 71-76.

LEONE FC, NELSON LS AND NOTTINGHAM RB. 1961. The folded normal distribution. Technometrics 3: 543-550.

LIMA MCS, CORDEIRO GM AND ORTEGA EMM 2015. A new extension of the normal distribution. J Data Sci 13: 385-408

MÜLLER JW. 1987. New light on powers of power series. Rapport BIPM 87: 15 p.

NELSEN WB. 1972. Graphical analysis of accelerated life test data with the inverse power law model. IEEE Trans Reliab R-21: 2-11

OHAGAN AND LEONARD T. 1976. Bayes estimation subject to uncertainty about parameter constraints. Biometrika 63: 201-202.

ORTEGA EMM, LEMONTE AJ, CORDEIRO GM AND DA-CRUZ JN. 2016. The odd Birnaum-Saunders regression model with applications to lifetime data. J Stat Theory Prac 10: 780-804

ROGERS WH AND TUKEY JW. 1972. Understanding some long-tailed symmetrical distributions. Stat Neerl 26: 211-226.

ROOKS A, SCHUMACHER A AND COORAY K. 2010. The power Cauchy distribution: derivation, description, and composite models.NSF-REU Program Reports. Available from http://www.cst.cmich.edu/mathematics/research/REU_and_LURE.shtml SLATER LJ. 1966. Generalized Hypergeometric Functions. Cambridge: Cambridge University Press.

SRIVATAVA HM AND MANOCHA L. 1984. A treatise on generating functions. Chichester: Ellis Harwood Limited Publishers. 
TAHIR MH, CORDEIRO GM, ALIZADEH M, MANSOOR M, ZUBAIR M AND HAMEDANI GG 2015. The odd generalized exponential family of distributions with applications. J Stat Dist Applic 2: Art. 1.

TAHIR MH, ZUBAIR M, CORDEIRO GM, ALZAATREH A AND MANSOOR M. 2016. The Poisson-X family of distributions. J Stat Comput Simul 86: 2901-2921.

TORABI H AND MONTAZERI NH. 2012. The gamma-uniform distribution and its application. Kybernetika 48: 16-30.

TORABI H AND MONTAZERI NH. 2014. The logistic-uniform distribution and its application. Commun Stat Simul Comput 43: 2551-2569.

WANG Y, HOSSAIN AM AND ZIMMER WJ. 2003. Monotone log-odds rate distribution in reliability analysis. Commun Stat Theory Methods 32: 2227-2244.

WIPER MP, GIRÓN FJ AND PESWEY A. 2008. Objective Bayesian inference for the half-normal and half-t distributions. Commun Stat Theory Methods 37: 3165-3185.

ZOGRAFOS K AND BALAKRISHNAN N. 2009. On families of beta- and generalized gamma-generated distributions and associated inference. Stat Methodol 6: 344-362.

\section{APPENDIX A}

For the sake of simplicity denote $\mathrm{H}(\mathrm{x}):=\overline{\mathrm{G}}(\mathrm{x})-\mathrm{G}(\mathrm{x})$ which satisfies $|\mathrm{H}(\mathrm{x})|<1$ being $\mathrm{G}(\mathrm{x}) \in(0,1)$. Then mutatis mutandis (Abramowitz and Stegun, 1972, pp. 87-8, Eqs. 4.6.22, 4.6.33)

$$
\begin{aligned}
\ln \frac{\overline{\mathrm{G}}(\mathrm{x})}{\mathrm{G}(\mathrm{x})} & =\ln \frac{1+\mathrm{H}(\mathrm{x})}{1-\mathrm{H}(\mathrm{x})}=2 \tanh ^{-1} \mathrm{H}(\mathrm{x})=\sum_{\mathrm{n} \geq 0} \frac{[\mathrm{H}(\mathrm{x})]^{2 \mathrm{n}+1}}{\mathrm{n}+\frac{1}{2}} \\
& =2 \mathrm{H}(\mathrm{x})_{2} \mathrm{~F}_{1}\left(\frac{1}{2}, 1 ; \frac{3}{2} ; \mathrm{H}^{2}(\mathrm{x})\right)
\end{aligned}
$$

where ${ }_{2} \mathrm{~F}_{1}(\cdot)$ stands for the familiar Gaussian hypergeometric function. The representation holds true for all $\mathrm{x} \in \mathbb{R}$ whenever the baseline function $\mathrm{G}(\mathrm{x}) \in(0,1)$.

The hypergeometric form of the error function reads (Abramowitz and Stegun, 1972, p. 297, Eq. 7.1.5)

$$
\operatorname{erf}(w)=\frac{2}{\sqrt{\pi}} \int_{0}^{w} e^{-x^{2}} d x=\frac{1}{\sqrt{\pi}} \sum_{n \geq 0} \frac{(-1)^{n} w^{2 n+1}}{n !\left(n+\frac{1}{2}\right)}=\frac{w}{\sqrt{\pi}}{ }_{1} F_{1}\left(\frac{1}{2} ; \frac{3}{2} ;-w^{2}\right) .
$$

For numerical evaluations in both cases the partial sums which turns out to be polynomials of hypergeometric type can be used.

\section{APPENDIX B}

The power series raised to positive integer powers reads as follows (Gradshteyn and Ryzhik, 2000; p. 17, Sect. 0. 314)

$$
S^{n}:=\left(\sum_{k \geq 0} a_{k} x^{k}\right)^{n}=\sum_{m \geq 0} b_{m} x^{m}, \quad n \in \mathbb{N}_{0}
$$

where the coefficients are given recursively

$$
\mathrm{b}_{0}=\mathrm{a}_{0}^{\mathrm{n}}, \quad \mathrm{b}_{\mathrm{m}}=\frac{1}{\mathrm{~m} \mathrm{a}_{0}} \sum_{\mathrm{k}=1}^{\mathrm{m}}[\mathrm{k}(\mathrm{n}+1)-\mathrm{m}] \mathrm{a}_{\mathrm{k}} \mathrm{b}_{\mathrm{m}-\mathrm{k}}, \quad \mathrm{m} \in \mathbb{N} .
$$


The real power case is investigated by Müller (1987; p. 3, Eq. (6a))

$$
S^{\mu}=\left(\sum_{k \geq 0} a_{k} x^{k}\right)^{\mu}=\sum_{k \geq 0} b_{k} x^{k} ; \quad b_{0}=1, b_{k}=\sum_{n=1}^{k}\left(\begin{array}{l}
\mu \\
n
\end{array}\right) \underbrace{\sum_{n} n ! \prod_{j=1}^{k} \frac{a_{j}}{\prod_{j} n_{j} !}}_{n c_{k}} .
$$

Here the summation (n) should be used $n_{1}+\cdots+n_{k}=n$ and $n_{1}+2 n_{2}+\cdots+k n_{k}=k$ upon all $0 \leq n_{j} \leq n$. On the other hand $\mathrm{n}_{\mathrm{k}}=\mathrm{B}_{\mathrm{k}, \mathrm{n}} /(\mathrm{k}-\mathrm{n})$ ! is written in the Bell's polynomial terminology.

Recalling in brief, the exponential partial Bell polynomials (Comtet 1974) are described by

$$
\exp \left(u \sum_{j \geq 1} x_{j} \frac{\mathrm{t}^{\mathrm{j}}}{j !}\right)=\sum_{n, k \geq 0} \frac{\mathrm{B}_{\mathrm{k}, \mathrm{n}}}{\mathrm{k} !} \mathrm{t}^{\mathrm{k}} \mathrm{u}^{\mathrm{n}}
$$

where

$$
\mathrm{B}_{\mathrm{k}, \mathrm{n}}=\mathrm{B}_{\mathrm{k}, \mathrm{n}}\left(\mathrm{x}_{1}, \mathrm{x}_{2}, \ldots, \mathrm{x}_{\mathrm{k}-\mathrm{n}+1}\right)=\sum_{(\mathrm{c})} \frac{\mathrm{k} !}{\mathrm{c}_{1} ! \mathrm{c}_{2} ! \cdots(1 !)^{\mathrm{c}_{1}(2 !)^{\mathrm{c}_{2}} \ldots}} \mathrm{x}_{1}^{\mathrm{c}_{1}} \mathrm{x}_{2}^{\mathrm{c}_{2}} \cdots,
$$

and the summation takes place over all integers $c_{1}, c_{2}, \cdots \geq 0$, which verify $c_{1}+2 c_{2}+3 c_{3}+\cdots=k$ and $\mathrm{c}_{1}+\mathrm{c}_{2}+\mathrm{c}_{3}+\cdots=\mathrm{n}$. These polynomials can be computed in Mathematica using the BellY $[\mathrm{k}, \mathrm{n},\{\mathrm{x} 1, \ldots, \mathrm{k}-$ $n+1\}]$ function and in Maple using the IncompleteBellB(k, n, z[1],z[2], ., z[k=n+1]) function. 